Juliana Abreu Talon

Roteirização de Veículos para Sistemas de Distribuição com Reabastecimento Diário

Dissertação de Mestrado (opção profissional)

Dissertação apresentada como requisito parcial para obtenção do grau de Mestre pelo Programa de PósGraduação em Engenharia de Produção do Departamento de Engenharia Industrial da PUC-Rio.

Orientador: Prof. Rafael Martinelli Pinto

Rio de Janeiro setembro de 2019 
Juliana Abreu Talon

\section{Roteirização de Veículos para Sistemas de Distribuição com Reabastecimento Diário}

Dissertação apresentada como requisito parcial para obtenção do grau de Mestre (opção profissional) pelo Programa de Pós-Graduação em Engenharia de Produção do Departamento de Engenharia Industrial do Centro Técnico Científico da PUC-Rio. Aprovada pela Comissão Examinadora abaixo.

Prof. Rafael Martinelli Pinto Orientador Departamento de Engenharia Industrial - PUC-Rio

Prof. Antonio Márcio Tavares Thomé Departamento de Engenharia Industrial - PUC-Rio

Prof. Orivalde Soares da Silva Júnior Departamento de Engenharia Industrial - PUC-Rio 
Todos os direitos reservados. É proibida a reprodução total ou parcial do trabalho sem autorização do autor e do orientador.

\section{Juliana Abreu Talon}

Graduou-se em Engenharia de Produção pela Pontifícia Universidade Católica do Rio de Janeiro em 2016.

Ficha Catalográfica

Talon, Juliana Abreu

Roteirização de Veículos para Sistemas de Distribuição com Reabastecimento Diário / Juliana Abreu Talon; orientador: Rafael Martinelli; - 2019.

56 f.: il. (color.); $30 \mathrm{~cm}$

Dissertação (mestrado) - Pontifícia Universidade Católica do Rio de Janeiro, Departamento de Engenharia Industrial, 2019.

Inclui bibliografia

1. Engenharia industrial - Teses. 2. Logística urbana. 3. Lojas de conveniência. 4. Otimização. 5. Problema de roteirização de veículos. I. Martinelli, Rafael. II. Pontifícia Universidade Católica do Rio de Janeiro. Departamento de Engenharia Industrial. III. Título.

CDD: 658.5 


\section{Agradecimentos}

Agradeço a minha família que pode me fornecer uma boa educação e sempre me apoiaram e incentivaram para alcançar meus objetivos.

Agradeço ao professor Rafael Martinelli pelos ensinamentos e orientação durante a elaboração deste trabalho.

Agradeço aos meus colegas de mestrado que compartilharam essa jornada comigo.

E por fim agradeço aos amigos que estiveram presentes nesta etapa e que de alguma forma contribuíram para o meu desenvolvimento. 


\section{Resumo}

Talon, Juliana Abreu; Martinelli Pinto, Rafael. Roteirização de Veículos Para Sistemas de Distribuição com Reabastecimento Diário. Rio de Janeiro, 2019. 56p. Dissertação de Mestrado (opção profissional) Departamento de Engenharia Industrial, Pontifícia Universidade Católica do Rio de Janeiro.

Nos últimos anos as empresas varejistas começaram a investir em modelos menores de lojas, voltando-se para o atendimento de conveniência, que busca atender os novos hábitos de consumo da população. No entanto, esse modelo de loja representa um grande desafio logístico para as empresas, uma vez que por serem pequenas essas lojas normalmente não possuem espaço para estoque, necessitando de abastecimentos frequentes. A logística urbana apresenta alguns obstáculos como as restrições de circulação por tipo de veículo e as janelas de tempo, tornando a roteirização adequada fundamental para entregar o produto correto, no momento correto e na quantidade correta, garantindo assim a redução de veículos, distância percorrida e custos logísticos. Desta forma, este trabalho busca contribuir para o reabastecimento ótimo de lojas de conveniência localizadas em grandes centros urbanos através da otimização de rotas, considerando restrições de circulação e janelas de tempo disponíveis para abastecimento. Para isto, um estudo de caso foi feito em uma empresa do setor varejista utilizando uma ferramenta de código aberto baseada no Excel para resolver a variante do problema de roteirização de veículos. A ferramenta utilizada para resolver casos reais da empresa em estudo, considera o planejamento médio da demanda diária assim como a capacidade e disponibilidade dos veículos, tempos de descarga e restrições de horário para recebimento e circulação de veículos. Os resultados do estudo para os cenários discutidos apresentam uma redução de até 32\% no frete da empresa, além de oportunidades de ganhos operacionais frente à atual operação da empresa.

\section{Palavras-chave}

Logística Urbana; Lojas de Conveniência; Otimização; Problema de Roteirização de Veículos. 


\section{Abstract}

Talon, Juliana Abreu; Martinelli Pinto, Rafael (Advisor). Vehicle Routing for Distribution Systems with Daily Replenishment. Rio de Janeiro, 2019. 56p. Dissertação de Mestrado (opção profissional) - Departamento de Engenharia Industrial, Pontifícia Universidade Católica do Rio de Janeiro.

In recent years retail companies have begun to invest in smaller store models, turning to the convenience service, which seeks to meet the new consumption habits of the population. However, this store model represents a major logistical challenge for companies, once they are small, usually do not have space for inventory and need frequent replenishments. City Logistics presents some obstacles such as traffic restrictions by vehicle type and time windows, making proper routing essential to deliver the right product at the right time and in the right amount, thus ensuring vehicle reduction, distance traveled and logistics costs. In this way, the objective of this paper is to contribute to the optimal replenishment of convenience stores located in large urban centers through an optimization of the routes, considering the traffic restrictions and the time windows available for supply. For this, a case study was done in a retail company using an Excel open source tool to solve the variant of the vehicle routing problem. The tool is used to solve real cases of the company under study, considering the average planning of daily demand as well as the capacity and availability of vehicles, unloading times and time constraints for receiving and circulating vehicles. The study results for the scenarios discussed present a reduction of up to $32 \%$ in the company's freight as well as opportunities for operating gains against the company's current operation.

\section{Keywords}

City Logistics; Convenience Stores; Optimization; Vehicle Routing Problem. 


\section{Sumário}

1. Introdução 12

$\begin{array}{lll}1.1 & \text { Objetivo Geral } & 14\end{array}$

1.2 Objetivos Específicos 14

$\begin{array}{lll}1.3 & \text { Estrutura } & 15\end{array}$

2 Referencial Teórico 16

2.1 Logística Empresarial 16

2.2 Distribuição Física 18

$\begin{array}{ll}2.2 .1 \text { Cross-Docking } & 19\end{array}$

2.2.2 Merge -in-Transit $\quad 19$

2.2.3 Hub-and-Spoke 20

$\begin{array}{ll}2.3 \text { City Logistics } & 21\end{array}$

2.4 Problema de Roteamento de Veículos (VRP) 23

3 Metodologia 28

3.1 Planejamento 29

3.2 Revisão Bibliográfica 29

3.3 Coleta de Dados 29

$\begin{array}{ll}3.4 \text { Aplicação } & 30\end{array}$

3.4.1 Formulação Matemática 30

3.4.2 VRP Spreadsheet Solver 32

3.5 Análise e Discussão dos Resultados 36

4 Estudo de Caso $\quad 37$

4.1 Apresentação da Empresa $\quad 37$

4.2 Coleta e Tratamento de Dados 38

4.3 Aplicação e Resultados $\quad 41$

4.3.1 Cenário $1 \quad 42$

4.3.2 Cenário $2 \quad 43$

4.3.3 Cenário $3 \quad 44$

$\begin{array}{ll}\text { 4.3.4 Cenário } 4 & 46\end{array}$

5 Considerações Finais $\quad 49$

5.1 Conclusões sobre os resultados obtidos 49 
5.2 Proposta de Estudos Futuros

50

6 Referências Bibliográficas 


\section{Lista de Figuras}

Figura 1: Atividades Logísticas na Cadeia de Suprimentos da Empresa 17 Figura 2: Estrutura da planilha do VRP Spreadsheet Solver 33 Figura 3: Solução VRP Spreadsheet Solver 34

Figura 4: Localização lojas e CD 40

Figura 5: Resultados da roteirização de veículos 47

Figura 6: Dimensionamento da frota de veículos 48 


\section{Lista de Tabelas}

Tabela 1: Características do VRP 25

Tabela 2: Capacidade e custo de frete por tipo de veículo 39

Tabela 3: Resultados cenário 1

Tabela 4: Resultados cenário 2

Tabela 5: Resultados cenário $3 \quad 45$

Tabela 6: Resultados cenário 4 


\section{Lista de Abreviações}

ALNS - Adaptive Large Neighborhood Search

CD - Centro de Distribuição

CLM - Council of Logistics Management

GA - Genetic Algorithms

GIS - Geographic Information System

ILS - Iterated Local Search

OD - Origem e Destino

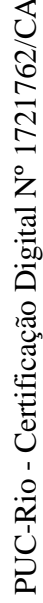

SCM - Supply Chain Management

TSP - Travelling Salesman Problem

VRP - Vehicle Routing Problem

VRPTW - Vehicle Routing Problem with Time Windows

SIS - Sequential Insertion Strategy

PIS - Parallel Insertion Strategy

NFIC - Nearest Feasible Insertion Criterion

MCFIC - Modified Cheapest Feasible Insertion Criterion 


\section{1. Introdução}

As lojas de conveniência se caracterizam por ter uma localização estratégica, horário de atendimento maior que as lojas convencionais e pela venda de itens alimentícios, tabacaria, higiene, dentre outros, atendendo assim uma necessidade de consumo imediato e conveniente dos clientes. O diferencial das lojas de conveniência em relação aos supermercados e hipermercados é a sua localização. Primeiramente, essas lojas estão distribuídas em maior quantidade pelas cidades e, principalmente, estão próximas às grandes avenidas, aos bairros residenciais e às áreas de maior movimento noturno de bares, restaurantes e discotecas. Oferecem atendimento e serviço com maior rapidez do que dos supermercados. As mercadorias são mais fáceis de serem encontradas e, além disso, estão junto a postos de gasolina (Ortigoza, 2010).

O primeiro formato de lojas de conveniência surgiu nos Estados Unidos, no final da década de 1920, buscando atender consumidores que buscavam produtos básicos perto de suas casas, quando outros estabelecimentos já estavam fechados. Com o desenvolvimento industrial americano após a $2^{\mathrm{a}}$ Guerra Mundial e com o novo posicionamento econômico do país, desencadeou-se uma mudança no modo de vida da população. Porém só a partir de 1970 as lojas de conveniência passaram a receber investimentos de grandes companhias norte americanas (News, 2007).

No Brasil esse modelo de loja surgiu em 1987 através de uma iniciativa da Shell e do grupo Pão de Açúcar e eram localizadas em postos de combustível (Plural , 2018). No entanto, com o passar dos anos e a mudança no comportamento do consumidor, grandes empresas varejistas estão expandindo suas áreas de atuação através de modelos menores de lojas, voltando-se para o atendimento de conveniência, que busca atender os novos hábitos de consumo da população.

Apesar da grave crise econômica que atinge o Brasil nos últimos anos, o setor de conveniência apresenta crescimento. Em 1994 o Brasil tinha cerca de 140 estabelecimentos e desde então apresenta um crescimento médio de $22 \%$ ao ano, atingindo 1630 lojas em 2001 e mais de 3 mil no final de 2003 (News, 2007). Em 
2016 o setor cresceu 10,8\% em faturamento e 8,8\% em número de lojas. O desempenho positivo e de crescimento desse modelo de lojas reflete, em parte, o investimento que se tem aportado para a expansão do canal e para o desenvolvimento de ofertas cada vez mais adequadas ao consumidor moderno (Sindicom, 2017), que hoje realiza cerca de $24 \%$ dos seus gastos fora de casa (News, 2007).

Porém apesar dos fortes investimentos e crescimento nos últimos anos, as lojas de conveniência ainda representam um grande desafio no mercado brasileiro, principalmente no que tange o seu abastecimento. Por serem estabelecimentos pequenos, normalmente com pouco espaço para estocagem de mercadorias, as lojas de conveniência demandam entregas frequentes. Assim, a falta de escala de entrega e a fragmentação dos pedidos são obstáculos que a indústria deverá superar (Sindicom, 2017), afim de atingirem elevados níveis de serviço e se manterem competitivas no mercado. Por outro lado, o transporte urbano de cargas contribui para a poluição do ar, poluição sonora, aumento do congestionamento, além da segurança nos centros urbanos (Talon et al., 2018), fazendo com que em muitas cidades os governos instituíssem medidas de restrição de circulação de tempo e tipo de veículo (Akyol et al., 2013).

Com restrições de circulação, problemas de poluição, congestionamento e segurança, a logística urbana busca através da otimização da circulação de mercadorias em áreas urbanas, a sustentabilidade, mobilidade e qualidade de vida nos grandes centros urbanos.

Como o principal objetivo no gerenciamento das cadeias de suprimento é entregar o produto correto, no momento correto, na quantidade adequada e com eficiência em relação ao custo de transporte (Razmi et al., 2013), a roteirização adequada é de fundamental importância para o planejamento de rotas, tendo como principal objetivo a redução de veículos, distância percorrida e custos logísticos.

Com o crescimento das cidades e consequentemente das trocas e distribuição de mercadorias, há um crescente interesse na otimização dos processos logísticos realizados nas áreas urbanas (Serna et al., 2012), uma vez que instituir janelas de tempo para circulação de veículos de carga é desafiador para os objetivos e interesses das partes envolvidas em atividades logísticas (Akyol et al., 2013). 
Com as margens de lucro estreitas, as empresas varejistas devem constantemente buscar excelência nas suas operações, deixando pouco espaço para desperdícios e ineficiências (Cachon, 2001). Desse modo as restrições de circulação de veículos e o tempo para a realização das entregas, juntamente com a necessidade de minimizar os custos de transporte tornam a distribuição de carga em centros urbanos um dos maiores desafios das empresas varejistas que estão migrando para o modelo de lojas de conveniência e precisam ter elevados níveis de serviços para se manterem competitivas no mercado.

Para isto, este trabalho busca responder às seguintes perguntas de pesquisa:

- Quais são os fatores que envolvem o planejamento de uma distribuição de mercadorias em centros urbanos?

- Qual o impacto da utilização da roteirização ótima na roteirização da empresa?

- Qual é a roteirização que minimiza os custos de frete/distância percorrida no abastecimento das lojas de conveniência?

\section{1 \\ Objetivo Geral}

Este estudo foi realizado a partir de um centro de distribuição e lojas de conveniência localizadas na cidade do Rio de Janeiro. O principal objetivo deste trabalho é contribuir para o reabastecimento ótimo das lojas de conveniência na cidade do Rio de Janeiro, minimizando os custos de frete, através da aplicação de um método metaheurístico para a resolução de um problema de roteirização de veículos.

\section{2}

\section{Objetivos Específicos}

Para alcançar o objetivo geral apresentado acima, foram considerados os seguintes objetivos específicos:

- Levantar as restrições para o abastecimento em meio urbano;

- Utilizar uma biblioteca em Excel para a resolução de um problema de roteirização de veículos com o objetivo de minimizar a distância percorrida e os custos de frete;

- Realizar uma análise de sensibilidade com os resultados obtidos no modelo; 
- Levantar os dados para o planejamento da roteirização como veículos e suas capacidades, restrições de horários, demanda e custos de transporte.

\section{3}

\section{Estrutura}

Além deste capítulo de caráter introdutório, o restante deste estudo segue organizado da seguinte forma: o Capítulo 2 apresenta o referencial teórico sobre os principais conceitos da logística empresarial, distribuição física, City Logistics e uma visão geral das pesquisas realizadas sobre roteirização de veículos em meio urbano.

No Capítulo 3 será apresentada a metodologia utilizada para a realização do estudo. No Capítulo 4 será apresentado o estudo de caso com apresentação da empresa, coleta e tratamento de dados e apresentação e análise dos resultados obtidos. No Capítulo 5 serão apresentadas as conclusões juntamente com a identificação de lacunas como oportunidades de pesquisas futuras. 


\section{2 Referencial Teórico}

Neste capítulo é apresentada uma revisão da literatura abordando os principais conceitos que se relacionam com o tema desta dissertação. A primeira seção apresenta os conceitos da logística empresarial sendo seguida de uma seção sobre distribuição física. A terceira seção apresenta os conceitos de City Logistics e por fim a quarta seção aborda o problema de roteamento de veículos (VRP) é o foco central deste trabalho.

\section{1}

\section{Logística Empresarial}

As primeiras aplicações significativas de logística foram desenvolvidas no setor militar (Rodrigue et al., 2002). Um general do exército francês sob o comando de Napoleão Bonaparte, definiu a logística como "a arte prática de movimentar exércitos". Durante a segunda Guerra Mundial, esse conceito se tornou ainda mais abrangente e as forças armadas entenderam que a logística compreendia todas as atividades relativas à provisão e administração de materiais, pessoal e instalações, além da obtenção e prestação de serviços de apoio (Dias et al., 2011).

Posteriormente, associada às atividades industriais, a logística foi definida pelo Council of Logistics Management (CLM) (Ballou, 2006) como:

"Logística é o processo de planejamento, implantação e controle do fluxo eficiente e eficaz de mercadorias, serviços e das informações relativas desde o ponto de origem até o ponto de consumo com o propósito de atender às exigências dos clientes".

Bowersox et al., (2014) definiram logística como a responsabilidade de projetar e administrar sistemas para controlar o transporte e a localização geográfica dos estoques de matérias-primas, de produtos em processo e acabados pelo menor custo total. 
Com a expansão dos mercados, queda de fronteiras mercantis e avanços da globalização, a conceituação contemporânea de logística engloba amplos horizontes externos às organizações e abrange fornecedores e clientes interligados a um propósito comum, passando a ser denominada Logística Empresarial ou "Supply Chain Management" (Buller, 2012).

O termo "Supply Chain Management" tem sido usado para denotar a integração das atividades de logística e distribuição física pelos atacadistas e varejistas, e os esforços dos fabricantes para integrar efetivamente compras e suprimentos com outras funções da empresa (Wisner et al., 2000).

Assim, a logística empresarial representa a integração do gerenciamento de materiais com a distribuição física, conforme apresentado na figura 1.

Figura 1: Atividades Logísticas na Cadeia de Suprimentos da Empresa

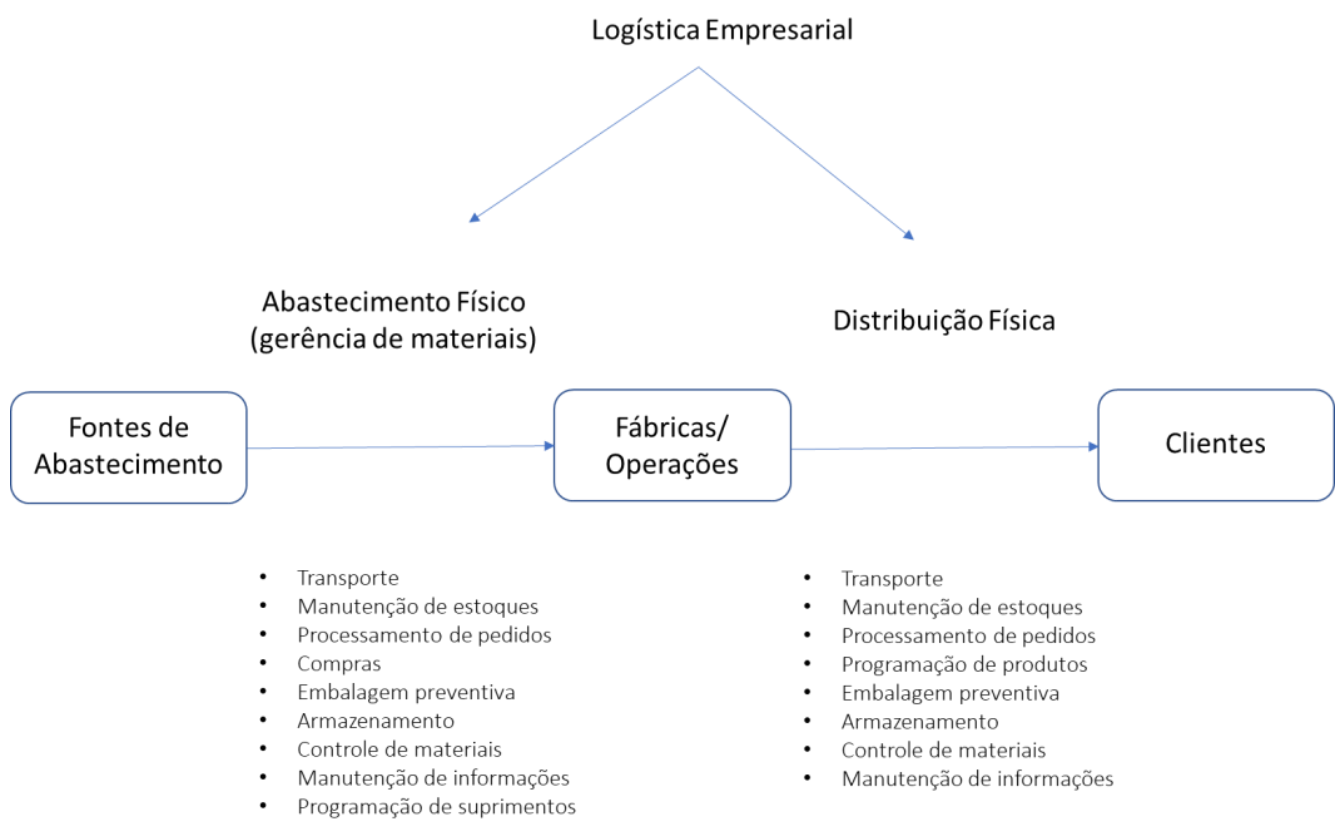

Fonte: Adaptado de Ballou (2006)

Conforme pode ser observado na Figura 1, a logística empresarial abrange toda a movimentação de materiais e mercadorias desde o seu recebimento nas fábricas ou centros de distribuição até sua saída para os clientes. Dentre as atividades que compõem a logística empresarial estão o transporte, manutenção de estoques, programação e processamento de pedidos, compras, controle de materiais, 
armazenamento e controle de informações. Este trabalho tem como foco o transporte para o cliente, se relacionando assim com a distribuição física, que será discutida na próxima seção.

\section{2 \\ Distribuição Física}

A distribuição de produtos é uma das principais atividades das empresas, pois define o sucesso no processo de atendimento aos seus clientes. A distribuição deve ser garantida em todos os componentes da cadeia de abastecimento no prazo e com a qualidade determinada. (Enomoto et al., 2007)

Assim a distribuição física abrange todas as funções de movimentação de manuseio de mercadorias, principalmente serviços de transporte (rodoviário, ferroviário, aéreo, marítimo e por dutos), transbordo e armazenamento (Hesse et al., 2004).

A distribuição física compreende o transporte, manutenção de estoques, processamento de pedidos, programação de produtos, embalagem preventiva, armazenamento, controle de materiais e manutenção de informações (Ballou, 2006).

Dentro da distribuição física, o transporte é um dos custos logísticos mais significativos. Mais de 60 centavos de cada dólar logístico são gastos com transporte. $\mathrm{O}$ custo de transporte está diretamente relacionado ao tipo de produto, ao tamanho da carga e à distância percorrida. Muitos sistemas logísticos de atendimento direto dependem de transportes de alta velocidade para pequenas cargas, o que é caro. Assim a consolidação de cargas se mostra como uma alternativa para a redução desses custos, uma vez que quanto maior a carga e a distância a ser transportada, menor o custo por unidade (Bowersox et al., 2014).

Para contornar os obstáculos existentes no abastecimento em centros urbanos as empresas varejistas e de logística podem adotar algumas estratégias como forma de otimizar suas operações e gerarem vantagem competitiva frente aos concorrentes. Assim, com base no trabalho de Talon et al. (2018) exemplos podem ser adotadas algumas estratégias para o abastecimento em meio urbano como o 
cross-docking, merge-in-transit e o hub-and-spoke, que são apresentadas nas próximas seções.

\subsection{1}

\section{Cross-Docking}

O objetivo do cross-docking é obter um fluxo contínuo de produtos dos fornecedores para os clientes movendo os produtos através de uma rede de distribuição sem armazená-los como estoque nos centros de distribuição (Buijs et al., 2016). Neste modelo de distribuição as cargas são entregues no terminal de cross-docking, descarregadas, classificadas, movidas e carregadas em veículos para a entrega nos próximos destinos da cadeia de abastecimento. Assim, o crossdocking é uma estratégia com um ponto de consolidação, que permite que pequenos volumes de carga sejam mesclados, de modo a lotar um caminhão e obter economias no transporte das mercadorias (Ross et al., 2008). Além disso, no crossdocking, os produtos ficam no estoque por um período de tempo muito menor que em um depósito tradicional, reduzindo assim o custo e a necessidade de espaço para armazenagem (Boloori et al., 2011).

No entanto, quando existe restrição de espaço, o número de caminhões chegando pode exceder a quantidade de docas disponíveis, gerando barreiras para a implementação do cross-docking uma vez que começam a acontecer filas de espera, sendo necessário um planejamento para evitar gargalos na operação (Choy et al., 2012).

\subsection{2}

\section{Merge -in-Transit}

O merge-in-transit é uma extensão do conceito de cross-docking combinados aos sistemas just-in-time. A operação merge-in-transit procura coordenar o fluxo dos componentes, gerenciando os respectivos lead times de produção e transporte, para que estes sejam consolidados em instalações próximas aos mercados consumidores no momento de sua necessidade, sem implicar em estoques intermediários. Normalmente é aplicado à distribuição de produtos de alto valor agregado, formado por multicomponentes que tem suas partes produzidas em 
diferentes plantas especializadas (Ilos, 2000). Neste modelo de distribuição é importante que as entregas sejam completas para os clientes, de modo que tudo chegue ao mesmo tempo, podendo-se assim atrasar o carregamento de alguns fornecedores, se necessário (Karkkainen et al., 2003). Esse modelo de distribuição também pode ser considerado como uma variação do milk run (processo logístico no qual se eliminam as várias entregas de fornecedores através de coleta sequenciada, utilizando-se o mesmo transporte), em que os itens são coletados nos diferentes fornecedores e enviados ao cliente em um embarque único (Juvella et al., 2018). Além disso, o uso desse método para a distribuição de cargas, permite que as empresas ofereçam um sortimento mais amplo de produtos, através de uma infraestrutura integrada de distribuição, sem a necessidade de armazenagem, contribuindo assim para a redução dos custos de estoque e distribuição, comparado ao modelo tradicional (point-to-point) de distribuição (Ala-Risku et al., 2003).

No entanto, o merge-in-transit é um modelo de distribuição que encontra barreiras para ser conduzido, devido à necessidade do gerenciamento de informações em todos os elos da cadeia de distribuição (Karkkainen et al., 2003), para garantir que as mercadorias estejam no lugar certo, no momento certo e na quantidade adequada.

\subsection{3 \\ Hub-and-Spoke}

O Hub-and-Spoke é um método de distribuição inicialmente aplicado ao setor aéreo, que provou ser eficiente em sistemas que envolvem várias origens e/ou destinos e um fluxo balanceado de mercadorias. Na década de 1990, este método se tornou o principal modelo de distribuição de carga empregado pela TNT, UPS, Fed-Ex, DHL e outras operadoras internacionais (Lumsden et al., 1999). Neste modelo de distribuição, os hubs ficam localizados em pontos onde a carga chega de várias origens ou vem de uma origem para vários destinos. Nesse ponto, a carga é reorganizada e enviada para outro destino intermediário $(h u b)$ ou destino final (spoke). O objetivo desse método é a redução de custos através da economia de escala com o transporte de grandes quantidades de cargas entre os hubs, de modo que os caminhões não façam viagens longas com pouca carga (Rodriguez et al., 2007). Assim, muitas empresas com prazos de entrega reduzidos, têm utilizado 
redes do tipo hub-and-spoke. Ao invés de se estabelecerem ligações diretas entre todas as filiais, cujos volumes de carga nem sempre justificam a frequência que seria necessária para atender os requisitos de nível de serviço, algumas filiais funcionam como pontos concentradores de carga, viabilizando um sistema de transferência eficiente, tanto em termos de custos quanto em qualidade de serviço, através da consolidação de cargas (Silva et al., 2004). Deste modo, este modelo apresenta benefícios, como permitir frequências mais altas de abastecimento e custos mais baixos, em comparação com o modelo tradicional de distribuição, onde o transporte das mercadorias é feito direto dos centros de distribuição para o destino final (Campbell, 1993).

Contudo, a definição ótima do número de hubs necessários para aumentar a eficiência da distribuição, a localização ótima para esses hubs e a definição de quais pontos de venda devem ser alocados ou não em cada $h u b$ são alguns dos desafios enfrentados para a implementação do hub-and-spoke (Chen, 2008). Além disso, devido ao longo prazo do planejamento estratégico de muitas empresas, é difícil prever a demanda por bens de consumo ao longo do tempo, podendo tornar a distribuição pelo modelo de hub-and-spoke ineficiente (Zapfel et al., 2016).

Este trabalho se relaciona com a distribuição física de mercadorias em e as restrições para o abastecimento em meio urbano, assim o conceito de logística urbana é discutido na próxima seção.

\section{3 \\ City Logistics}

Devido ao aumento da população e crescimento econômico nas áreas urbanas, a demanda por transporte urbano de carga tem aumentado (Cherrett, et al., 2012). O transporte de mercadorias constitui um importante fator de habilitação para as atividades econômicas e sociais que ocorrem em áreas urbanas (Crainic, et al., 2009). Um grande número de diferentes tipos de fluxos de mercadorias atravessa constantemente um ambiente urbano, incluindo bens de consumo, materiais de construção, resíduos, correios, entre outros. Esses fluxos ocupam cerca de um quarto do tráfego das ruas de uma cidade. Além disso, as mercadorias transportadas necessitam de carga e descarga, armazenamento, condicionamento e embalagem, exigindo assim mais uso do espaço urbano (Dablanc, 2007). 
No entanto, o número de veículos que circulam dentro das cidades deve continuar crescendo em ritmo acelerado. Os principais fatores que contribuem para esse crescimento são as atuais práticas de produção e distribuição, baseadas em baixos níveis de estoque e entregas pontuais, além do crescimento do comércio eletrônico, que gera um aumento significativo no número de entregas necessárias. (Crainic et al., 2009).

Assim, City Logistics é o termo utilizado para denotar os conceitos e práticas logísticas envolvidas nas entregas em áreas urbanas, o transporte last mile, com problemas específicos de atrasos causados por congestionamentos, falta de local para estacionar, interação com outros usuários das vias urbanas, dentre outros. Concentra-se principalmente no transporte de mercadorias e tem como objetivo final a redução do choque de interesses entre as empresas de logística e os outros stakeholders envolvidos na mobilidade urbana (Muñuzuri et al., 2005).

Contudo, o transporte em meio urbano é um dos fatores mais significativos para a insustentabilidade das cidades (Quak et al., 2009). A distribuição de mercadorias em áreas urbanas através do transporte rodoviário, geralmente conhecida como City Logistics, contribui para o congestionamento do tráfego, assim como é afetada pelo congestionamento, gerando impactos ambientais e altos custos logísticos (Barceló et al., 2007).

Para melhorar o desempenho do sistema de transporte urbano de mercadorias, muitas políticas têm sido propostas, incluindo restrições de horários para circulação de veículos de carga, restrições de tipo de veículo, políticas de carga e descarga, políticas fiscais, bases de transbordo e consolidação de cargas (Danielis et al., 2010).

As janelas de tempo limitam os períodos dentre os quais os veículos de carga podem entrar nos centros das cidades, normalmente fora do horário comercial (Akyol et al., 2018). À medida que a pressão por janelas de tempo aumenta, o número de entregas em lojas que podem ser combinadas em uma única viagem diminui, ou seja, a empresa de varejo (que armazena e vende mercadorias) é forçada a usar veículos extras e percorrer longas distâncias para realizar as entregas das lojas, resultando em um aumento no custo do varejista. Além disso as janelas de 
tempo para entrega em lojas podem ser alteradas com o tempo, e para um varejista é difícil e caro se adaptar a essas mudanças (Akyol et al., 2018).

Com isso, as empresas de transporte enfrentam um grande desafio e são obrigadas a fornecer níveis de serviço cada vez mais elevados para atender às necessidades dos clientes (Taniguchi et al., 2002).

Um caminho a seguir é a colaboração entre empresas, provedores de serviços logísticos, cidadãos e o setor público. Trabalhando em conjunto, as partes interessadas aumentam a sua eficiência por meio do compartilhamento de recursos, como veículos, centros de consolidação ou distribuição de carga e serviços de entrega last mile. Essa colaboração poderia levar a menos veículos nas áreas urbanas, menos poluição e menores preços de mercadorias. No entanto, experiências anteriores dessa prática logística mostram que esse tipo de colaboração não é eficiente pois exige esforços adicionais de planejamento e controle (Cleophas et al., 2019).

Este trabalho se concentra na atividade de transporte em centros urbanos e apresenta uma aplicação do problema de roteamento de veículos, que será explicado na próxima seção.

\section{4 \\ Problema de Roteamento de Veículos}

As decisões referentes à configuração dos movimentos de um veículo para atender às demandas em diversos pontos de uma rede de transporte são classificadas como problemas de roteamento e normalmente envolvem a especificação de uma sequência de pontos que um veículo deve visitar (Raff, 1983). Desse modo o problema do roteamento de veículos (VRP - Vehicle Routing Problem) pode ser descrito como o problema de planejar rotas otimizadas de entrega ou coleta de um ou vários depósitos para um número de cidades ou clientes dispersos geograficamente, sujeito à restrições (Laporte, 1992).

Segundo (Erdoğan, 2017), o problema de roteamento de veículos é um dos problemas de otimização mais encontrados em logística, que visa minimizar o custo 
das operações de transporte por uma frota de veículos operando a partir de uma base ou centro de distribuição.

Contudo, na prática existem várias variantes deste problema, devido à diversidade de regras operacionais e restrições encontradas nas aplicações da vida real. Assim, o VRP deve ser visto como uma classe de problemas (Laporte, 2009).

Uma das principais restrições nos problemas de roteamento da realidade, são as restrições de tempo para circulação de veículos. Desse modo, o problema de roteamento de veículos com janelas de tempo (Vehicle Routing Problem with Time Windows - VRPTW) é uma das principais variações do problema clássico de roteamento de veículos. Assim como o VRP clássico, este tipo de problema pode ser descrito como o problema para planejar rotas de menor custo de um ou mais depósitos para um conjunto de pontos geograficamente dispersos, minimizando a distância total percorrida ou a duração das rotas. As rotas devem ser projetadas de tal forma que cada ponto seja visitado apenas uma vez por exatamente um veículo dentro de um determinado intervalo de tempo, todas as rotas começam e terminam no mesmo depósito, e as demandas totais de todos os pontos em uma rota particular não devem exceder a capacidade do veículo. Os parâmetros como demanda e janela de tempo são conhecidos (Bräysy et al., 2005).

A Tabela 1 ilustra algumas das principais variações que o problema de roteamento de veículos pode apresentar. 
Tabela 1: Características do VRP

\begin{tabular}{|c|c|}
\hline Características & Possibilidades \\
\hline \multirow{2}{*}{ 1. Tamanho da frota disponível } & - Um veículo \\
\hline & -Múltiplos veículos \\
\hline \multirow{3}{*}{ 2. Tipo de frota disponível } & -Homogênea \\
\hline & -Heterogênea \\
\hline & -Veículos especiais \\
\hline \multirow{2}{*}{ 3. Garagem de veículos } & -Único depósito \\
\hline & -Múltiplos depósitos \\
\hline \multirow{2}{*}{ 4. Natureza da demanda } & -Determinística \\
\hline & -Estocástica \\
\hline \multirow{3}{*}{ 5. Localização da demanda } & -Nós \\
\hline & $-\operatorname{Arcos}$ \\
\hline & -Mista \\
\hline \multirow{4}{*}{ 6. Estrutura da rede } & -Indireta \\
\hline & -Direta \\
\hline & -Mista \\
\hline & -Euclidiana \\
\hline \multirow{3}{*}{$\begin{array}{l}\text { 7. Restrição de capacidade do } \\
\text { veículo }\end{array}$} & -Imposta (veículos com mesma capacidade) \\
\hline & -Imposta (veículos com capacidades diferentes) \\
\hline & -Não imposta (capacidade ilimitada) \\
\hline \multirow{3}{*}{ 8. Tempo máximo de rota } & -Imposto (mesmo para todas as rotas) \\
\hline & -Imposto (diferente para rotas diferentes) \\
\hline & -Não imposto \\
\hline \multirow{4}{*}{ 9. Operação } & -Somente coletas \\
\hline & -Somente entregas \\
\hline & -Mista (coletas e entregas) \\
\hline & -Entregas parceladas \\
\hline \multirow{2}{*}{ 10. Custos } & -Variáveis \\
\hline & -Fixos \\
\hline \multirow{4}{*}{ 11. Objetivos } & -Minimizar os custos das rotas \\
\hline & -Minimizar a soma dos custos fixos e variáveis \\
\hline & -Minimizar o número de veículos \\
\hline & $\begin{array}{l}\text {-Maximizar a função utilidade pelo serviço, conveniência ou } \\
\text { pelas prioridades do cliente }\end{array}$ \\
\hline
\end{tabular}

Fonte: Adaptado de Raff (1983)

O primeiro problema de roteirização a ser estudado foi o Problema do Caixeiro Viajante (TSP - Travelling Salesman Problem). Segundo (Chen et al., 2011) o TSP é um importante tópico de pesquisa, no qual um caixeiro viajante deseja visitar várias cidades, mas cada uma só pode ser visitada uma única vez. Desse modo, o objetivo do problema é minimizar a distância percorrida pelo caixeiro viajante. 
Assim, o primeiro modelo para resolver problema de roteamento de veículos foi proposto por (Dantzig et al., 1959) como uma generalização do problema do caixeiro viajante, introduzindo-se algumas condições.

Apesar do VRP ser uma generalização problema do caixeiro viajante, na prática ele é um problema muito mais difícil de resolver (Laporte, 2009). O VRP é classificado como um problema NP-difícil. Portanto, métodos de otimização exata podem ser difíceis para a resolução desses problemas em tempos de CPU aceitáveis, uma vez que o problema envolve conjuntos de dados do mundo real que são muito grandes (Kumar et al., 2015). Para a resolução dos problemas de roteamento de veículos podem ser usados métodos exatos ou heurísticas e metaheurísticas. Os métodos exatos são capazes de resolver problemas com aproximadamente 200 vértices (Pecin et al., 2017). Como normalmente os problemas reais de roteamento de veículos excedem esse tamanho e as soluções precisam ser determinadas rapidamente, a maioria dos algoritmos utilizados na prática são heurísticas ou metaheurísticas (Laporte, 2009).

As heurísticas realizam uma exploração limitada no espaço de busca e geralmente geram boas soluções em um tempo computacional baixo. Nas metaheurísticas a ênfase está em realizar uma busca mais profunda no espaço de solução. Normalmente esse método combina técnicas sofisticadas de buscas na vizinhança, estruturas de memória e recombinação de soluções. A qualidade das soluções obtidas por esse método normalmente é muito maior que a obtida com uma heurística clássica, no entanto exige um tempo computacional maior (Laporte et al., 2000).

O algoritmo de Clarke and Wright (1964) é a heurística mais conhecida para o VRP. Aplica-se a problemas nos quais a quantidade de veículos é uma variável de decisão e funciona bem para problemas orientados ou não. (Laporte et al., 2000). A heurística conhecida como Savings Algorithm começa com uma solução inicial composta por $n$ rotas de ida e volta $(0, i, 0)$, onde (i $\in \mathrm{V} \backslash\{0\})$ e $\mathrm{V}$ representa o conjunto de vértices a serem visitados. A cada iteração ela mescla uma rota que termina em $i$ com uma rota que começa em $j$ maximizando a economia $s_{i j}=c_{i 0}+$ $c_{0 j}-c_{i j}$ e fornecendo a rota viável. O processo para quando não é mais possível formar rotas (Laporte, 2009). 
Entre as metaheurísticas destacam-se o Adaptive Large Neighborhood Search (Pisinger et al., 2007), Iterated Local Search (Subramanian et al., 2010) e Genetic Algorithms (Vidal et al., 2014).

O Adaptive Large Neighborhood Search (ALNS), é uma estrutura de pesquisa local, na qual vários algoritmos simples competem para mudar a solução atual. Em cada iteração um algoritmo é escolhido para destruir a solução atual e um algoritmo é escolhido para reparar a solução. A nova solução é aceita se atender aos critérios definidos pela estrutura de pesquisa local aplicado no nível principal (Pisinger et al., 2007).

A Iterated Local Search (ILS) é uma metaheurística que consiste em aplicar repetidamente um algoritmo de busca local a soluções obtidas por meio de pequenas modificações em uma das soluções ideias localmente visitadas anteriormente. O método realiza busca locais e mecanismos de perturbação. A fase de busca local realiza movimentos que melhoram a solução atual. Uma vez que a vizinhança não tem mais nenhum movimento de melhoria possível, inicia-se a fase de perturbação (Essafi et al., 2008). Os mecanismos de perturbação consistem em múltiplos movimentos para alterar clientes de uma rota para outra. Assim, sempre que uma pesquisa local é realizada as rotas associadas às soluções locais ideais podem ser adicionadas a um conjunto de rotas (Route Pool). O método decide se deseja adicionar ou não essas rotas com base no número médio de clientes por rota e no desvio entre as melhores soluções atuais (Subramanian et al., 2013).

Os algoritmos genéticos são uma técnica de otimização, cujo conceito básico é imitar a evolução de uma espécie, de acordo com a teoria Darwinista de "sobrevivência do mais forte" (Leardi, 2009). A metaheurística para esses problemas conta com busca local, operadores genéticos e métodos avançados para o gerenciamento da diversidade. As especificidades do problema estão restritas à uma parte do método e são tratadas por meio de componentes de atribuição, sequenciamento e avaliação de rotas, sendo automaticamente selecionados e adaptados para fornecer operadores fundamentais para o gerenciamento das especificidades dos atributos (Vidal et al., 2014). 


\section{3 \\ Metodologia}

Este trabalho apresenta a aplicação de um modelo matemático para a roteirização de veículos. Segundo (Silva et al., 2001), trata-se de uma pesquisa aplicada, pois tem como objetivo gerar conhecimento para uma aplicação prática e resolução de um problema específico. A abordagem do problema estudado é quantitativa, uma vez que tudo pode ser quantificável. Do ponto de vista dos objetivos esse trabalho se caracteriza como uma pesquisa exploratória, por apresentar pesquisas bibliográficas e estudo de caso. Por fim, do ponto de vista dos procedimentos técnicos, o estudo se caracteriza como uma pesquisa bibliográfica, experimental, estudo de caso e participante.

A pesquisa bibliográfica se baseia em materiais já publicados, como artigos, revistas, livros, entre outros. A pesquisa experimental identifica o objeto de estudo e seleciona variáveis que podem influenciá-lo.

O estudo de caso se caracteriza por um estudo profundo de determinando objeto, permitindo um conhecimento detalhado sobre o mesmo. Segundo (Yin, 2009) o estudo de caso é uma investigação empírica de um fenômeno contemporâneo dentro de um contexto real, especialmente quando os limites entre o fenômeno e o contexto não são claramente evidentes. É uma história de um fenômeno passado ou atual, extraído de diversas fontes de evidência que pode incluir dados de observações diretas e entrevistas, bem como arquivos públicos ou privados. (Leonard-Barton, 1990).

Por fim, a pesquisa é participante por ter interação com os membros envolvidos no problema em estudo.

Desse modo, para o desenvolvimento deste trabalho, a metodologia foi dividida nas seguintes etapas, adaptada da proposta de pesquisa de (Silva et al., 2001): planejamento; revisão bibliográfica; coleta de dados; aplicação; análise e discussão dos resultados. Cada uma das etapas será detalhada nas seções seguintes. 


\section{1 \\ Planejamento}

Nesta etapa é feita a definição do tema a ser estudado, justificativa, formulação do problema, definição dos objetivos gerais e específicos, perguntas de pesquisa e estrutura para desenvolvimento da pesquisa.

\section{2 \\ Revisão Bibliográfica}

A segunda etapa é a revisão bibliográfica. A revisão bibliográfica consiste em um levantamento de trabalhos de cunho teórico e caráter empírico, identificando lacunas na literatura que justifiquem a pesquisa.

Para este trabalho a revisão bibliográfica foi feita através da busca em base de dados como Scopus e Google Schoolar. As buscas foram feitas por título, autor ou palavras-chaves. As principais palavras-chaves utilizadas para pesquisa foram: "city logisticis"; "distribuition"; "vehicle routing problem"; "convenience stores", "VRP”; “optimization”; "logistics", "urban freight distribution”.

\section{3 \\ Coleta de Dados}

A terceira etapa é a coleta de dados. Nesta etapa, determinam-se os dados que serão coletados e os métodos a serem utilizados, podendo ser entrevistas, visitas, análise documental, entre outros.

Para este trabalho os dados foram obtidos através de bases de dados da empresa em estudo. Foram levantados dados como a demanda diária em $\mathrm{m}^{3}$ para cada ponto de abastecimento; o tipo de veículo que cada uma das lojas a serem abastecidas podia receber, considerando-se as restrições de circulação; a capacidade de cada veículo; os custos de frete para cada tipo de veículo que poderia ser utilizado e o horário disponível para recebimento de mercadorias.

Para distâncias entre os pontos a serem atendidos e o centro de distribuição, considerado como ponto de partida e ponto final da rota, foi feita uma matriz origem destino (OD). Para o cálculo da distância entre os pontos foi utilizada uma API do 
Bing Maps (https://www.bing.com/maps/?cc=br) e feita a busca por distâncias através da latitude e longitude de cada ponto.

\section{4 Aplicação}

A quarta etapa é aplicação do método escolhido para análise do problema abordado no trabalho.

Neste trabalho é feita a aplicação de uma ferramenta de roteirização que tem como objetivo minimizar os custos de transporte para o abastecimento de lojas de conveniência, considerando as restrições de circulação de veículos e as janelas de tempo para realização das entregas. Para a aplicação do modelo é utilizado o $V R P$ Spreadsheet Solver, uma extensão do Microsoft Excel.

\subsection{1 \\ Formulação Matemática}

A formulação matemática proposta por Erdoğan (2017) é uma adaptação da proposta por Pisinger et al. (2007), devido à sua flexibilidade para atender muitas variantes do VRP. A formulação foi adaptada para as características deste estudo e é descrita abaixo.

Seja $G=(V, A)$ um grafo e, 0 o centro de distribuição, onde $0 \in V$ :

$V_{d}$ - Conjunto de centros de distribuição (CDs)

$V_{m}$ - Conjunto de lojas que devem ser visitadas

$\mathrm{V}$ - Conjuntos de vértices, onde $V=\{0\} \cup V_{m}$

A - Conjunto de arcos da rede

K - Conjunto de veículos disponíveis para atendimento das lojas

\section{Parâmetros:}

$\hat{q}_{i}$ - Demanda de mercadoria a ser entregue em cada loja i

$s_{i}$ - Tempo de serviço para atender cada loja $\mathrm{i}$ 
$\left[a_{i}, b_{i}\right]$ - Janela de tempo disponível para atendimento de cada loja i

$Q^{k}$ - Capacidade de cada veículo k

$\widehat{D}^{k}$ - Limite de tempo para utilização de cada veículo $\mathrm{k}$

$W^{k}$ - Duração da jornada de trabalho

$\hat{d}_{i j}-$ Tempo entre cada par de loja $(i, j)$

$c_{i j}^{k}$ - Custo de transporte entre cada par de loja (i,j) para um determinado veículo $\mathrm{k}$

\section{Variáveis de Decisão:}

$x_{i j}^{k}$ - Igual a 1 se o veículo k atravessar o arco (i,j); 0 caso contrário

$Y_{i}^{k}$ - Igual 1 caso o veículo $\mathrm{k}$ atenda a loja i; 0 caso contrário

$z_{i j}^{k}$ - Demanda transportada no veículo k no $\operatorname{arco}(\mathrm{i}, \mathrm{j})$

$t_{i}^{k}$ - Horário que o veículo k chega para atender cada loja i.

Desse modo a formulação adaptada para o problema em estudo segue conforme abaixo:

$$
\operatorname{Minimizar} \sum_{k \in K} \sum_{i \in V_{m}} c_{0 i}^{k} x_{0 i}^{k}
$$

Sujeito a:

$$
\begin{array}{ll}
\sum_{k \in K} Y_{i}^{k}=1 & \forall_{i} \in V_{m} \\
\sum_{j \in V \backslash\{i\}} z_{j i}^{k}-\sum_{j \in V \backslash\{i\}} z_{i j}^{k}=\hat{q}_{i} Y_{i}^{k} & \forall_{i} \in V_{c}, k \in K \\
z_{i j}^{k} \leq Q^{k} x_{i j}^{k} & \forall(i, j) \in A, k \in K \\
t_{i}^{k}+\left(\hat{d}_{i j}+s_{i}\right) x_{i j}^{k}-W^{k}\left(1-x_{i j}^{k}\right) \leq t_{j}^{k} & \forall(i, j) \in A: j \in V_{c}, k \in K \\
a_{i} \leq t_{i}^{k} \leq b_{i}-s_{i} & \forall_{i} \in V_{c}, k \in K \\
\sum_{(i, j) \in A} \hat{d}_{i j} x_{i j}^{k} \leq \widehat{D}^{k} & \forall(i, j) \in A, k \in K \\
x_{i j}^{k} \in\{0,1\} & \forall(i, j) \in A, k \in K \\
Y_{i}^{k} \in\{0,1\} & \forall_{i} \in V_{c}, k \in K
\end{array}
$$




$$
\begin{array}{ll}
z_{i j}^{k} \geq 0 & \forall(i, j) \in A, k \in K \\
t_{i}^{k} \geq 0 & \forall_{i} \in V_{c}, k \in K
\end{array}
$$

A função objetivo minimiza os custos de frete das rotas para o abastecimento das lojas de conveniência. A origem dos veículos é sempre o centro de distribuição (0), uma vez que o frete pago é por viagem realizada e não se baseia na distância percorrida pelo veículo. A restrição (2) garante que cada loja seja atendida somente uma vez. A restrição (3) é uma restrição de conservação de fluxo entre o centro de distribuição de origem do veículo e as lojas que ele deverá atender. A restrição (4) garante que a capacidade do veículo não seja excedida. A restrição (5) fornece a estrutura para as janelas de tempo. Desse modo, o horário de chegada de um veículo $\mathrm{k}$ à uma loja $i$ somado ao tempo de serviço na loja e ao tempo de deslocamento até uma loja $j$, deve ser igual ou anterior ao horário que o veículo deve chegar à loja $j$. A restrição (6) define os limites das janelas de tempo para atendimento de cada loja. A restrição (7) restringe a jornada de trabalho para o abastecimento das lojas durante o dia. As restrições (8), (9), (10) e (11) são restrições de não negatividade das variáveis utilizadas.

\section{4 .2}

\section{VRP Spreadsheet Solver}

Para resolver o problema de roteirização de veículos que minimiza a distância percorrida e os custos de frete, foi utilizado o VRP Spreadsheet Solver no Microsoft Excel. O VRP Spreadsheet Solver é uma ferramenta de código aberto baseada no Excel, utilizada para resolver variantes do problema de roteirização de veículos. (Erdoğan, 2017)

Segundo (Erdoğan, 2015) esta ferramenta permite a roteirização de veículos para o atendimento de até 200 pontos diferentes em 1 hora de tempo de CPU e trabalha com as seguintes restrições:

- Os veículos possuem um custo fixo por viagem, mais um adicional por km rodado, porém não é possível adicionar nenhum outro custo de frete.

- As distâncias e os tempos e viagem são conhecidos. 
- Cada ponto de parada com exceção do centro de distribuição, só pode ser visitada por um veículo e uma vez, não sendo possível dividir entregas e em cada parada deve ser entregue toda a demanda.

- A demanda e o tempo gasto em cada parada são conhecidos.

A biblioteca apresenta os dados dos elementos do problema de roteamento de veículos (VRP) em planilhas separadas e adota um fluxo incremental de informações conforme ilustra a Figura 2 (Erdoğan, 2017).

Figura 2: Estrutura da planilha do VRP Spreadsheet Solver

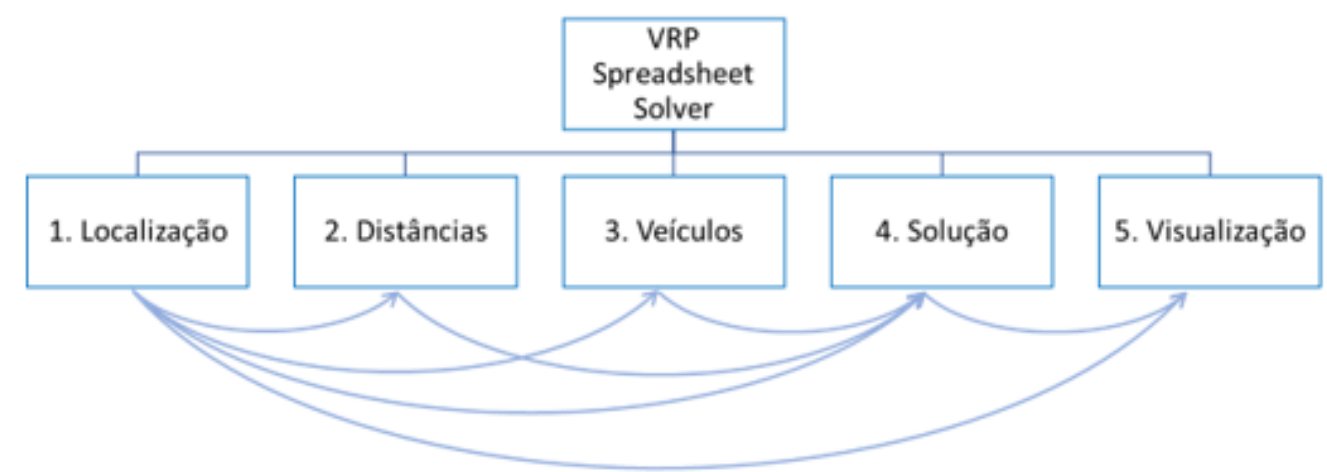

Fonte: Adaptado Erdogan (2017)

- Localização: Na aba de localização são colocados os dados de cada a ponto a ser visitado nas rotas; como nome; endereço; coordenadas geográficas; janela de tempo para recebimento e a demanda de cada ponto. As coordenadas geográficas podem ser obtidas através de um serviço GIS (Geographic Information Service) disponível na internet, como por exemplo, Google Maps ou Bing Maps. Para este trabalho foi utilizado o Bing Maps.

- Distâncias: Na aba de distâncias são calculados as distâncias e o tempo de percurso entre dois pontos, já definidos na aba de localização também utilizando o serviço de GIS. 
- Veículos: Na aba de configuração dos veículos, é determinada a quantidade de veículos (por tipo) em cada centro de distribuição. Os custos são definidos como um custo fixo por veículo e um custo variável por km percorrido. Adicionalmente é definida a capacidade do veículo e o tempo máximo de duração da viagem.

-Solução: Na aba de solução são exibidas as listas com as paradas de cada veículo, os tempos para realização do serviço, os custos, a distância percorrida e o tempo total gasto.

- Visualização: Esta aba é opcional e pode ser utilizada para se obter uma visualização das rotas geradas. Ela exibe um mapa com a região da rota sugerida, através de um serviço da web de GIS (Geographic Information Service).

Para resolver a formulação proposta, o VRP Spreadsheet Solver é baseado na metaheurística Adaptive Large Neighborhood Search (ALNS) proposta por (Pisinger et al., 2007). O pseudocódigo adaptado e proposto por (Erdoğan, 2017) é descrito na Figura 3. 
1 Início (CDs, Lojas, Distâncias, Tempo, Veículos)

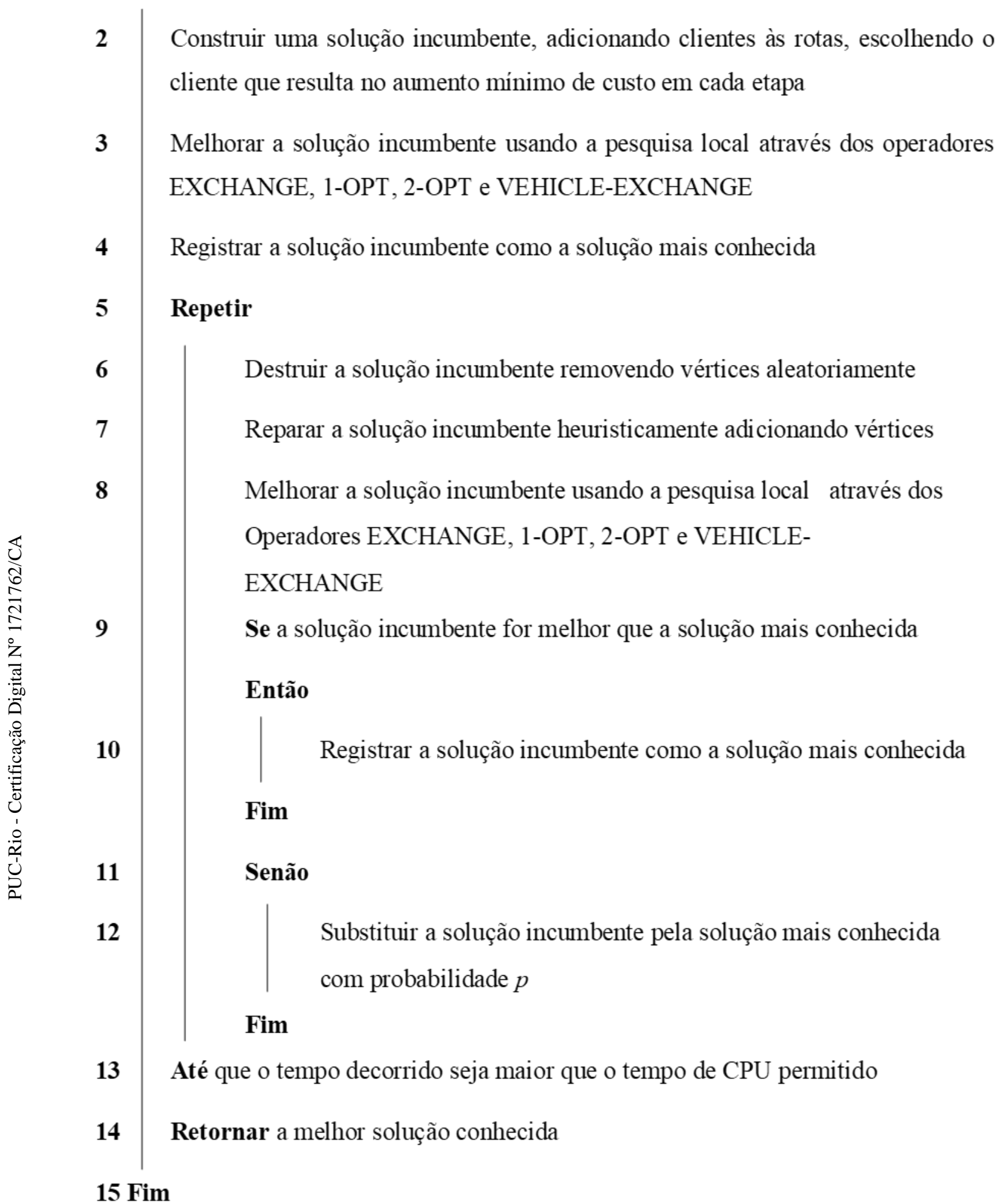

Fonte: Adaptado de Erdogan (2017)

Segundo (Erdoğan, 2017), quatro operadores de busca local foram utilizados no pseudocódigo, conforme descrito abaixo. 
- EXCHANGE: procura por todos os possíveis pares de lojas a serem atendidas em uma determinada solução e verifica se a troca delas resultaria em uma solução melhor para a função objetivo.

-1-OPT: verifica a possibilidade de remover cada loja dentro de uma determinada solução e reinserí-la em uma posição diferente dentro das rotas para melhorar o resultado da função objetivo.

-2-OPT: verifica a possibilidade de remover dois arcos da solução de uma vez. O arco do cliente $a$ ao cliente $b$ e o arco do cliente $c$ ao cliente $d$. Posteriormente é adicionado o arco do cliente $a$ ao cliente $d$ e o arco do cliente $c$ ao cliente $b$, verificando se é possível obter uma solução que melhore o resultado da função objetivo.

-VEHICLE EXCHANGE: tenta trocar todas as lojas nas rotas com dois veículos de tipos diferentes, em busca de melhores soluções para a função objetivo, sendo especialmente útil em casos de frota heterogênea.

Após a execução do algoritmo e com base nos pontos apresentados na seção 3.4.1 a solução encontrada pelo VRP Spreadsheet Solver lista as lojas que devem ser visitadas por cada veículo em cada roteiro gerado, a demanda dentro de cada veículo, a distância percorrida, o tempo de percurso, horário estimado que cada loja será visitada e o custo de cada uma das rotas.

\section{5}

\section{Análise e Discussão dos Resultados}

A quinta etapa é a análise e discussão dos resultados obtidos englobando todas as etapas anteriores e validando se os objetivos estabelecidos no início do estudo foram alcançados. Além disso, nesta etapa também é descrita a contribuição acadêmica da pesquisa realizada e as principais oportunidades de pesquisas futuras. 


\section{4 \\ Estudo de Caso}

Este capítulo tem como objetivo resolver o problema de roteamento de veículos para o atendimento de lojas de conveniência com reabastecimento diário. O estudo foi feito na cidade do Rio de Janeiro e considerou um conjunto de 24 lojas para atendimento por um centro de distribuição. A Seção 4.1 apresenta a descrição da empresa em estudo. A Seção 4.2 apresenta os dados que foram coletados e os tratamentos necessários, seguida da Seção 4.3 onde é feita a aplicação do método de roteirização e são apresentados os resultados obtidos para os cenários analisados.

\section{1 Apresentação da Empresa}

O presente estudo foi realizado em uma empresa brasileira do setor varejista, fundada em 1929 no Estado do Rio de Janeiro. Atualmente a empresa conta com mais de mil lojas físicas, localizadas em todos os estados brasileiros e com quatro centros de distribuição (CDs), localizados nos estados do Rio de Janeiro, São Paulo, Minas Gerais e Pernambuco, que são responsáveis pelo abastecimento das lojas da companhia. Adicionalmente às lojas já existentes, a companhia está desenvolvendo o novo modelo de negócio através das lojas de conveniência, que apresentam um mix de produtos mais voltado para o atendimento de necessidades de consumo imediato, como os itens alimentícios, por exemplo. Contudo, com o grande investimento nas lojas de conveniência da empresa e o aumento do número de lojas em ritmo acelerado, essas lojas representam um grande desafio para a empresa no que tange o seu abastecimento, uma vez que por serem pequenas e normalmente sem espaço para estoque, necessitam de reabastecimentos frequentes.

A operação realizada pelos centros de distribuição visa abastecer todas as lojas da companhia, atendendo suas respectivas demandas na frequência correta de abastecimento. Os centros de distribuição operam em três turnos e o gerente de 
transporte é responsável por estabelecer as rotas e alocar a demanda das lojas dentro dos veículos, de acordo com a sua capacidade, a janela de recebimento de cada loja e a restrição de circulação de veículos. No entanto, para abastecer suas lojas, a empresa encontra alguns desafios, relacionados a City Logistics, que envolvem restrições de circulação de alguns veículos de carga em meio urbano. Além disso, outros desafios internos à operação da empresa são as janelas de tempo que as lojas possuem para recebimento de mercadorias e a falta de veículos adequados para o abastecimento em centros urbanos, principalmente em épocas de alta demanda, fazendo com que a empresa tenha elevados gastos com o frete de suas mercadorias. Deste modo, com o objetivo de melhorar o nível de serviço prestado pelos centros de distribuição da empresa em estudo, foi realizado um estudo de roteirização de veículos, para minimizar as distâncias percorridas durantes as entregas e os custos de frete. Para a elaboração desta dissertação foi considerado apenas o CD do Rio de Janeiro e o modelo de lojas de conveniência da empresa, localizadas no estado do Rio de Janeiro.

\section{2 \\ Coleta e Tratamento de Dados}

Os dados utilizados foram obtidos através de bases de dados fornecidas pela empresa, referentes a um período de dois meses, sem sazonalidade na demanda. A empresa usa frota terceirizada para o abastecimento de suas lojas e o modelo de conveniência possui três tipos de veículos disponíveis, de acordo com as restrições de circulação e capacidade de recebimento das lojas. Os modelos de veículos disponíveis para o abastecimento das lojas de conveniência podem ser visualizados na Tabela 2, que apresenta também a capacidade e o custo de cada modelo por viagem. Por motivos de confidencialidade das informações da empresa, os valores referentes ao custo de frete foram alterados. Para isso o valor do veículo T1 foi fixado em 30 e os valores de T2 e T3 foram escalonados com base em T1. Não foi considerada a restrição com número de veículos disponíveis por tipo na operação, de modo que a empresa possa dimensionar a frota necessária para atender sua demanda. 
Tabela 2: Capacidade e custo de frete por tipo de veículo

\begin{tabular}{ccr}
\hline Tipo de Veículo & Capacidade $\left(\mathbf{m}^{\mathbf{3}}\right)$ & Custo de Frete \\
\hline T1 & 8 & 30,00 \\
T2 & 12 & 34,08 \\
T3 & 20 & 35,92 \\
\hline
\end{tabular}

Fonte: Autor (2019)

A capacidade de cada veículo foi definida de acordo com a ocupação média realizada pelo centro de distribuição (CD), em um período de dois meses, sem sazonalidade de demanda e considerando-se uma cubagem $\left(\mathrm{m}^{3}\right)$ padrão para cada tipo de veículo. O custo de frete, assim como a capacidade, foi definido pela média do custo por tipo de veículo para o abastecimento das lojas e não considera um valor para o retorno do veículo ao centro de distribuição, sendo cobrado apenas pela saída do CD. Cada veículo deve iniciar e terminar sua rota no centro de distribuição e, a carga transportada não pode exceder a capacidade do veículo.

As coordenadas geográficas do CD e das lojas foram obtidas através do Bing Maps e são apresentadas na Tabela A, localizada nos apêndices deste trabalho. A Figura 4 ilustra a localização do CD e das lojas em estudo. 
Figura 4: Localização lojas e CD

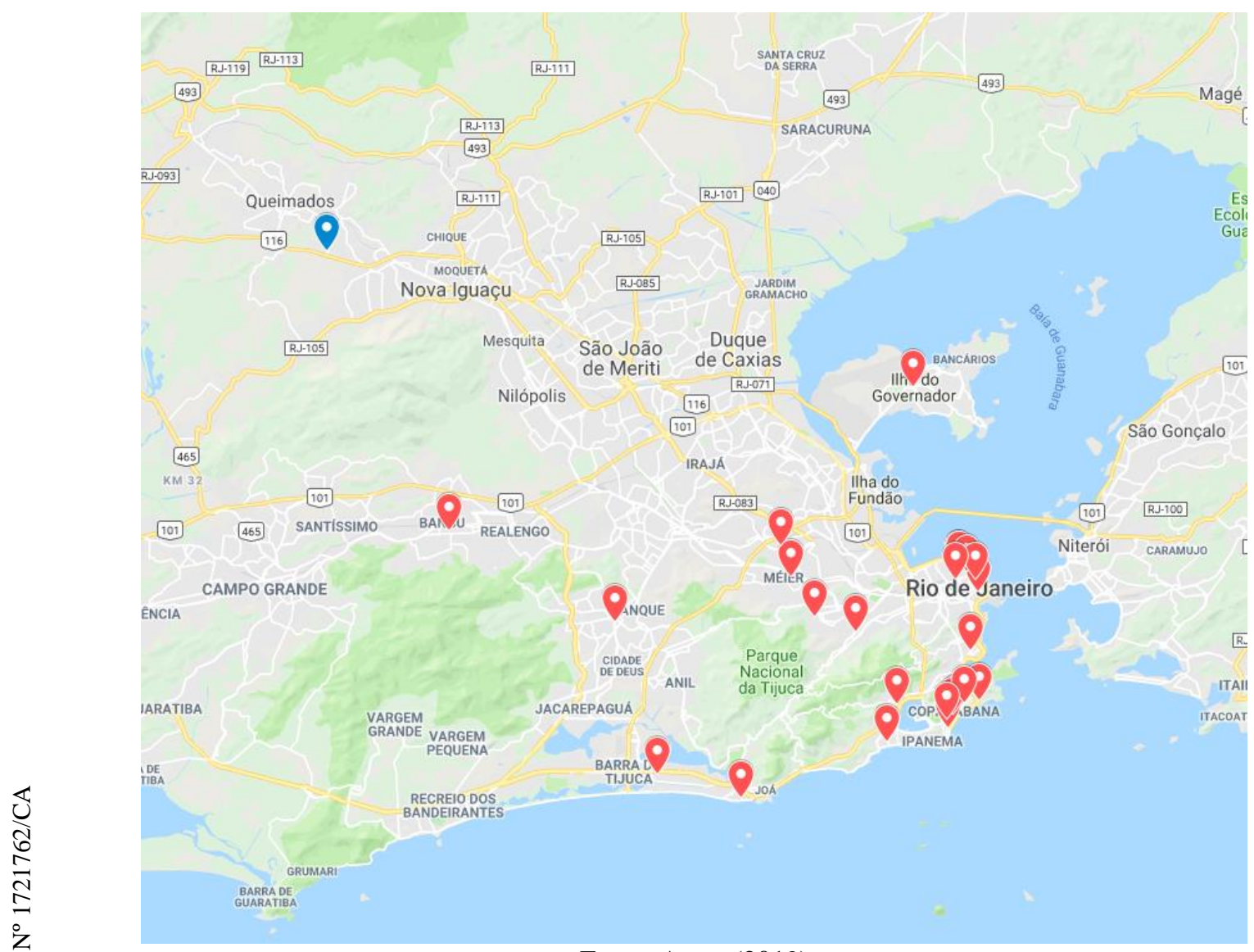

Fonte: Autor (2019)

Posteriormente, para o centro de distribuição e as lojas de conveniência, foi construída uma matriz origem/destino (O/D) assimétrica, através do Bing Maps com as distâncias e tempos de deslocamento entre os pontos a serem visitados. A Tabela B, localizada nos apêndices deste trabalho, apresenta a matriz OD com as distâncias e os tempos de deslocamento entre cada par de pontos, incluindo os tempos de retorno para o centro de distribuição.

A restrição de tempo de ciclo, estabelece que não podem ser excedidas dez horas por dia, incluindo as paradas para descarga nas lojas. O tempo de descarga em loja foi considerado de duas horas, sendo esse o tempo médio histórico da operação da companhia e a janela de tempo para recebimento de cada loja foi obtida através da base de dados da empresa, tendo um intervalo de três horas.

O CD da empresa opera 24 horas por dia, no entanto foi considerado que os veículos podem sair para realizar as entregas em loja a partir das seis horas da manhã, uma vez que todas as lojas consideradas no estudo recebem mercadorias apenas durante o dia. 
A demanda diária das lojas foi obtida através de uma base de dados da empresa referente a um período de dois meses. Foram excluídas da base de dados demandas muito baixas, referentes a abastecimentos especiais de alguns itens, que não refletem o abastecimento padrão da loja, e demandas muito elevadas que podem corresponder ao abastecimento inicial para inauguração, também não refletindo o padrão de abastecimento da loja. Assim, para a aplicação do estudo, foi considerada a demanda média diária por loja durante o período da base de dados.

Atualmente a roteirização de veículos da companhia em estudo é feita de forma manual pela equipe de expedição e transporte do centro de distribuição e estima-se que são necessários uma média de nove veículos para o abastecimento das 24 lojas em estudo a um custo médio de 287,33 por dia. O tipo de veículo T1 considerado como uma opção para o abastecimento não é utilizado na atual roteirização adotada pela empresa, de modo que apenas veículos T2 e T3 realizam o abastecimento das lojas de conveniência. Assim, a utilização da ferramenta de roteirização busca diminuir o atual custo de transporte da empresa. A seção seguinte apresenta a aplicação de uma biblioteca em Excel e os resultados obtidos em cada cenário analisado.

\section{3 Aplicação e Resultados}

Esta seção apresenta o modelo com os dados da empresa em estudo, resolvido em quatro cenários. O primeiro cenário retrata a realidade da operação da empresa com janelas de tempo definidas para recebimento de mercadorias em loja e tempo médio de descarga de duas horas por loja. No segundo cenário foram retiradas as janelas de tempo para recebimento, possibilitando a entrega de mercadorias em qualquer horário do dia, e considerando o tempo médio de descarga de duas horas. O terceiro cenário avalia uma possível redução no tempo de descarga em loja para 10 minutos por metro cúbico e mantém as janelas de recebimento. Por fim, o quarto cenário analisa o tempo médio de descarga de $10 \mathrm{~min} / \mathrm{m}^{3} \mathrm{sem}$ janelas de tempo para entrega em loja.

Após o cálculo das distâncias e tempos entre o centro de distribuição e as lojas, juntamente com os dados obtidos através da base de dados da empresa referentes aos veículos disponíveis, inicia-se o processo de solução do problema. 
Para a solução é utilizada o VRP Spreadsheet Solver seguindo os passos descritos na Seção 3.4.2 deste trabalho e um computador Intel Core i5 2,7GHz com 8GB de memória. A ferramenta utilizada considera um tempo de CPU de sessenta segundos para geração das rotas. Os resultados obtidos para cada cenário analisado são apresentados a seguir.

\subsection{1 \\ Cenário 1}

O primeiro cenário é o que mais se aproxima da atual realidade da empresa. Neste cenário, para atender a demanda das 24 lojas em estudo são necessários oito veículos, sendo três veículos do tipo 1 (T1), quatro veículos do tipo 2 (T2) e um veículo do tipo 3 (T3). Assim, o custo total do transporte para esse abastecimento é de 262,25 por dia. A Tabela 3 apresenta o resumo com o resultado obtido para esse cenário assim como as lojas que serão atendidas por cada veículo.

Tabela 3: Resultados cenário 1

\begin{tabular}{|c|c|c|c|c|c|}
\hline Veículo & Tipo de Veículo & Rota & Custo de Frete & Distância Percorrida (km) & Tempo (h) \\
\hline 1 & $\mathrm{~T} 1$ & CD-13-04-16-CD & 30,00 & 112,94 & $09: 24$ \\
\hline 2 & $\mathrm{~T} 1$ & CD-01-15-CD & 30,00 & 100,49 & 06:59 \\
\hline 3 & T1 & CD-12-17-02-CD & 30,00 & 128,83 & $08: 47$ \\
\hline 4 & $\mathrm{~T} 2$ & CD-22-19-14-CD & 34,08 & 133,32 & 08:01 \\
\hline 5 & $\mathrm{~T} 2$ & CD-11-05-06-CD & 34,08 & 104,57 & $08: 48$ \\
\hline 6 & $\mathrm{~T} 2$ & CD-10-24-09-CD & 34,08 & 107,01 & 09:54 \\
\hline 7 & $\mathrm{~T} 2$ & CD-03-07-23-20-CD & 34,08 & 108,59 & 09:42 \\
\hline 8 & T3 & CD-21-08-18-CD & 35,92 & 97,87 & 08:05 \\
\hline Total & & & 262,25 & 893,62 & 69:40:00 \\
\hline
\end{tabular}

Fonte: Autor (2019)

Comparando o resultado obtido no cenário 1 com a atual processo de planejamento de rotas que a empresa tem para o abastecimento das lojas em análise, podemos observar que apenas com a utilização de uma ferramenta adequada à roteirização de veículos pode-se obter um ganho de aproximadamente 8,7\%. Além do ganho financeiro, o número de veículos necessários também diminuiu de nove para oito. A redução dos custos e do número de veículos podem indicar que com a utilização da ferramenta para roteirização, estão sendo adotados veículos com capacidades mais adequadas a demanda diária. Desse modo, apenas o uso da 
ferramenta já é capaz de gerar ganhos para a companhia, sem que haja alteração nos horários disponíveis para entrega de mercadorias nas lojas ou redução do tempo de descarga.

\subsection{2}

\section{Cenário 2}

O segundo cenário é uma variação do primeiro, excluindo-se a restrição do horário de recebimento das lojas, no entanto, mantendo o tempo médio de descarga de duas horas por loja. Assim, com esse cenário pode-se observar uma redução de $13 \%$ no custo de frete em relação ao primeiro cenário analisado. Sem a restrição de janelas de tempo para entrega de mercadorias nas lojas, os veículos podem ser mais bem ocupados, atender mais lojas e finalizar as entregas em menos tempo, uma vez que não precisam aguardar o horário de entrega praticado atualmente caso cheguem antes na loja. Com isso há uma redução no número de veículos nesse cenário, passando de oito para sete veículos, sendo três do tipo 1 (T1), três do tipo 2 (T2) e um do tipo 3 (T3). Com a redução no número de veículos, a empresa pode obter além do ganho financeiro do transporte um ganho operacional, uma vez que com menos veículos são necessários menos pessoas para conferência e carregamento. Além disso menos veículos libera espaço nas docas de carregamento do centro de distribuição. Desse modo, com a análise dos resultados obtidos nesse cenário, podese concluir que uma mudança nos horários de recebimento das lojas a serem atendidas pode gerar ganhos operacionais e financeiros para a operação da empresa. A Tabela 4 apresenta um resumo dos resultados obtidos no segundo cenário.

Tabela 4: Resultados cenário 2 


\begin{tabular}{|c|c|c|c|c|c|}
\hline Veículo & Tipo de Veículo & Rota & Custo de Frete & Distância Percorrida (km) & Tempo (h) \\
\hline 1 & T1 & CD-10-24-15-CD & 30,00 & 112,94 & $07: 36$ \\
\hline 2 & $\mathrm{~T} 1$ & CD-13-12-18-08-CD & 30,00 & 109,88 & $09: 53$ \\
\hline 3 & $\mathrm{~T} 1$ & CD-04-16-CD & 30,00 & 91,00 & $05: 23$ \\
\hline 4 & $\mathrm{~T} 2$ & CD-11-06-01-CD & 34,08 & 94,67 & $07: 22$ \\
\hline 5 & $\mathrm{~T} 2$ & CD-17-19-10-09-CD & 34,08 & 127,69 & 09:49 \\
\hline 6 & $\mathrm{~T} 2$ & CD-07-23-14-05-CD & 34,08 & 102,46 & $09: 28$ \\
\hline 7 & T3 & CD-21-03-22-02-CD & 35,92 & 86,52 & 09:09 \\
\hline Total & & & 228,17 & 725,17 & $58: 40: 00$ \\
\hline
\end{tabular}

Fonte: Autor (2019)

Em relação ao atual processo de roteamento adotado pela empresa, o cenário 2 apresenta ganhos ainda mais significativos que o anterior, podendo gerar uma economia de aproximadamente $20 \%$ em relação aos custos de transporte. Esse resultado reforça a possibilidade de uma redefinição dos horários para atendimento das lojas, além da necessidade da utilização de veículos adequados a demanda. Além disso, a redução no número de veículos de nove para sete pode também gerar ganhos operacionais. Apesar do custo de frete da empresa não possuir um valor variável por $\mathrm{km}$ rodado, a redução no número de veículos reduz a distância percorrida para atendimento das lojas, conforme pode ser observado no cenário 2 que apresenta uma redução de 19\% em relação ao cenário 1.

Assim como a distância percorrida, o tempo total de atendimento das lojas também diminui no cenário 2. Isso pode ser explicado pela flexibilização das janelas de recebimento das lojas, reduzindo o tempo ocioso dos veículos aguardando o horário disponível para atendimento. Comparando o cenário 2 ao cenário 1 é possível obter uma redução de $16 \%$ no tempo total para abastecimento.

\subsection{3}

\section{Cenário 3}

O terceiro cenário apresenta uma melhora em relação a operação de abastecimento das lojas, adotando-se uma média de $10 \mathrm{~min} / \mathrm{m}^{3}$ para descarga das mercadorias, definido com base em uma análise empírica realizada pela empresa. Com a nova média de tempo para descarga, pode-se obter uma redução dos custos de frete de aproximadamente $24 \%$ em relação ao primeiro cenário e de $13 \%$ em relação ao segundo. Além disso, com a nova média de tempo para descarga das 
mercadorias, obteve-se também uma redução no número de veículos necessários, distância percorrida e tempo para atendimento das lojas, uma vez que com um atendimento mais eficiente, mais lojas podem ser atendidas por veículo, respeitando a restrição de tempo de jornada de trabalho. Ademais, os ganhos operacionais identificados no cenário 2 também podem ser observados nesse cenário, como espaço em doca e menos mão de obra necessária para conferência e carregamento. Para este cenário são necessários seis veículos, divididos em dois do tipo 1 (T1), três do tipo 2 (T2) e um veículo do tipo 3 (T3). A Tabela 5 apresenta o resumo com os resultados desse cenário e a rota realizada por cada veículo.

Tabela 5: Resultados cenário 3

\begin{tabular}{|c|c|c|c|c|c|}
\hline Veículo & Tipo de Veículo & Rota & Custo de Frete & Distância Percorrida (km) & Tempo (h) \\
\hline 1 & T1 & CD-23-20-16-CD & 30,00 & 109,03 & $08: 28$ \\
\hline 2 & T1 & CD-07-10-24-CD & 30,00 & 106,54 & $07: 36$ \\
\hline 3 & $\mathrm{~T} 2$ & $C D-21-13-C D$ & 34,08 & 122,15 & $06: 23$ \\
\hline 4 & T2 & CD-17-19-14-05-15-CD & 34,08 & 139,27 & 09:21 \\
\hline 5 & $\mathrm{~T} 2$ & CD-12-08-18-04-09-CD & 34,08 & 135,16 & 09:49 \\
\hline 6 & T3 & CD-03-22-11-01-06-02-CD & 35,92 & 99,62 & 09:38 \\
\hline Total & & & 198,17 & 711,77 & 51:15:00 \\
\hline
\end{tabular}

Fonte: Autor (2019)

Com a alteração do tempo de descarga para uma média de $10 \mathrm{~min} / \mathrm{m}^{3}$ a redução dos custos de frete da companhia pode chegar a $31 \%$ para o abastecimento das lojas de conveniência em estudo, sem que haja alteração no atual horário de recebimento de mercadorias praticado. Além disso, nesse cenário a quantidade de veículos é ainda menor, saindo de nove veículos atuais para seis veículos.

Apesar deste cenário considerar a restrição de janela de tempo para recebimento, a nova média de tempo para descarga de mercadorias gera uma redução na distância percorrida e um ganho de $26 \%$ no tempo de abastecimento quando comparado ao cenário 1, o qual também utiliza restrição de janela de tempo para atendimento. 


\subsection{4 Cenário 4}

O quarto e último cenário analisado propõe um tempo médio de descarga de $10 \mathrm{~min} / \mathrm{m}^{3}$ e a retirada da restrição de horário para atendimento das lojas, podendo ocorrer a entrega em qualquer horário do dia. Assim, esse cenário se mostrou como o mais econômico em relação aos custos de frete da companhia, apresentando uma redução de aproximadamente $25 \%$ em relação ao primeiro cenário, $14 \%$ em relação ao segundo e $1 \%$ em relação ao terceiro. Apesar de não ter tido uma redução no número de veículos em relação ao cenário anterior, a eliminação da restrição de janela de tempo para recebimento nas lojas permitiu um novo arranjo nos tipos de veículos necessários e consequentemente uma redução nos custos de transporte. Como a redução dos custos é pouco significativa do terceiro para o quarto cenário, podemos observar que apenas a melhora na eficiência da descarga em loja já é capaz de gerar ganhos importantes em relação ao frete da empresa, caso não seja possível a alteração do horário de recebimento das lojas. Esse cenário, assim como o anterior, conta com seis veículos, sendo três veículos tipo 1 (T1), um tipo 2 (T2) e dois veículos tipo 3 (T3). Os resultados com as rotas geradas para cada veículo são apresentados na Tabela 6.

Tabela 6: Resultados cenário 4

\begin{tabular}{|c|c|c|c|c|c|}
\hline Veículo & Tipo de Veículo & Rota & Custo de Frete & Distância Percorrida (km) & Tempo (h) \\
\hline 1 & T1 & CD-04-18-13-CD & 30,00 & 110,67 & $08: 57$ \\
\hline 2 & T1 & CD-22-01-15-CD & 30,00 & 98,04 & 05:09 \\
\hline 3 & $\mathrm{~T} 1$ & CD-07-20-16-CD & 30,00 & 110,29 & 09:54 \\
\hline 4 & $\mathrm{~T} 2$ & CD-12-17-19-10-08-CD & 34,08 & 133,23 & 09:13 \\
\hline 5 & T3 & CD-03-21-06-02-CD & 35,92 & 89,77 & 07:59 \\
\hline 6 & T3 & CD-11-05-14-23-24-09-CD & 35,92 & 105,02 & 08:53 \\
\hline Total & & & 195,92 & 647,00 & 50:05:00 \\
\hline
\end{tabular}

Fonte: Autor (2019)

Este cenário, quando comparado ao atual processo da empresa, pode alcançar uma redução nos custos de frete de em média 31,8\%. O cenário propõe o tempo médio de descarga de mercadoria em $10 \mathrm{~min} / \mathrm{m}^{3}$ e elimina a restrição de horários para atendimento das lojas. Em relação ao tempo para atendimento das lojas esse cenário apresenta uma redução de $28 \%$ em relação ao cenário 1 e $15 \%$ em relação ao cenário 2, o qual também desconsidera a restrição de janela de tempo para 
recebimento. Com isso, a possibilidade de uma nova definição de horários de abastecimento das lojas em estudo, juntamente com uma operação de descarga mais eficiente, torna este cenário o mais econômico e com menor tempo e distância percorrida entre os analisados e com os melhores benefícios financeiros e operacionais para a empresa.

A Figura 5 apresenta um resumo com os resultados obtido nos quatro cenários analisados e um comparativo com o atual roteamento de veículos realizado na operação da empresa.

Figura 5: Resultados da roteirização de veículos

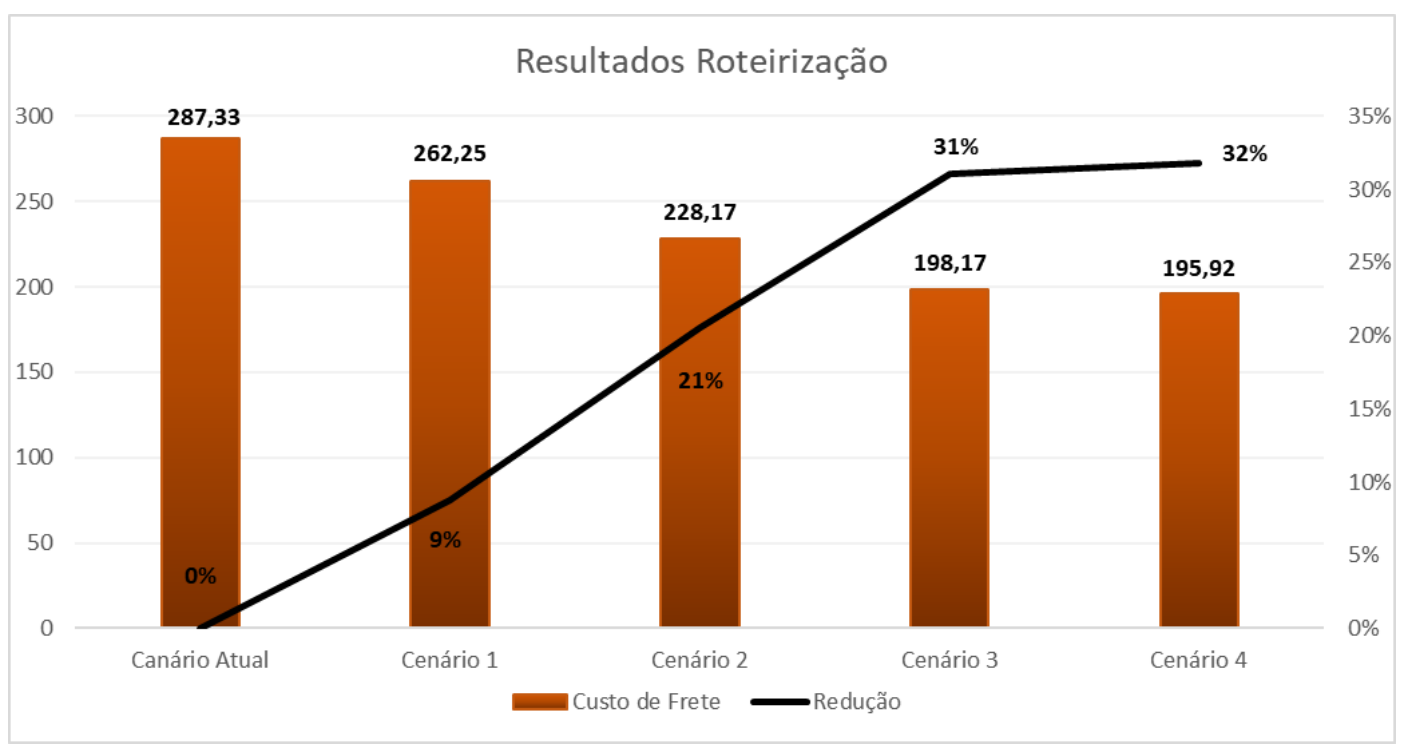

Fonte: Autor (2019)

Os resultados apresentados na Figura 5 evidenciam que o atual método de planejamento de rotas utilizado pela empresa apresenta ineficiências, uma vez que com a utilização de uma ferramenta de roteirização foi possível obter reduções no custo de frete para todos os cenários analisados.

O cenário 4 se mostrou o mais eficiente e econômico para a operação da empresa. Para se obter o resultado esperado é necessária a adequação do tempo de descarga da média atual de 2 horas por lojas para $10 \mathrm{~min} / \mathrm{m}^{3}$ e a alteração dos horários de recebimento das lojas para que possa ser feito um melhor compartilhamento de cargas dentro dos veículos, assim como a redução do número de veículos necessários na operação, tempo de atendimento e distância percorrida. 
Contudo, a alteração das janelas de tempo para recebimento de mercadorias pode não ser um processo simples de alteração, uma vez que depende do quadro de funcionários presentes na loja no horário agendado para atendimento, podendo haver então a necessidade de um redimensionamento da mão de obra necessária nos turnos de funcionamento de cada loja.

Desse modo, o cenário 3 pode ser considerado como uma boa opção para redução de custos de transporte, uma vez que os resultados obtidos são próximos aos do cenário 4 e não se faz necessária a alteração nos horários de entrega das mercadorias.

Em relação ao número de veículos necessários na operação, os quatro cenários também se mostraram mais eficientes que o atual dimensionamento de frota da empresa. A Figura 6 apresenta um resumo comparativo com os resultados obtidos.

Figura 6: Dimensionamento da frota de veículos

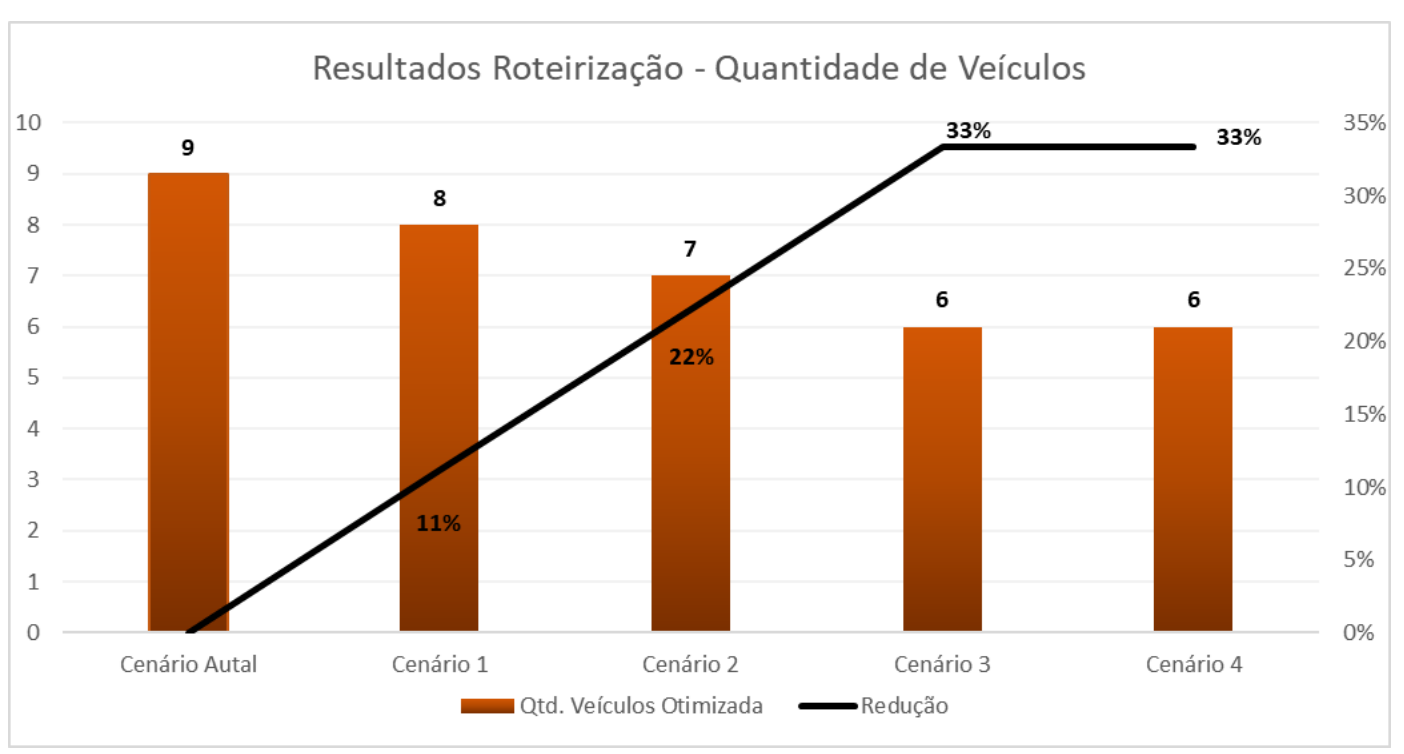

Fonte: Autor (2019)

A redução no número de veículos necessários para o abastecimento das lojas de conveniência em estudo permite que além da redução do custo de transporte a empresa tenha ganhos operacionais. Com uma quantidade menor de veículos, são necessárias menos pessoas para a conferência e carregamento dos veículos no CD. 


\section{5 Considerações Finais}

Este capítulo apresenta as considerações sobre os resultados obtidos com o trabalho e as propostas de estudos futuros.

\section{1}

\section{Conclusões sobre os resultados obtidos}

Este trabalho estuda o problema do roteamento de veículos para um sistema de distribuição com o reabastecimento diário de lojas de conveniência. As lojas de conveniência são menores, normalmente sem espaço para estoque de mercadorias, representando assim um desafio logístico para as empresas desse setor, no que tange seu abastecimento frequente e em pequenos volumes. Deste modo, este trabalho se propõe a minimizar os custos de frete para o abastecimento das lojas da empresa estudada. Para isso, o estudo realizado é aplicado a um conjunto de lojas localizadas na cidade do Rio de Janeiro de uma empresa do setor varejista através da utilização de uma biblioteca em Excel para a resolução do problema de roteamento de veículos.

Assim, respondendo a primeira pergunta de pesquisa proposta no capítulo 1 deste trabalho para se obter o planejamento ótimo de um sistema de distribuição de mercadorias em centros urbanos é preciso ter conhecimento sobre as restrições de circulação por tipo de veículo e horários de circulação permitidos. Além disso é preciso que a empresa tenha a frota adequada disponível no momento correto, um sistema de descarga em loja eficiente e horários de recebimento em lojas definidos de forma a viabilizar o maior número de entregas possíveis por veículo. Para tal, faz-se importante a utilização de ferramentas de roteirização como a utilizada neste trabalho.

Com os resultados obtidos, a ferramenta utilizada para análise se mostrou eficiente, uma vez que os quatro cenários analisados apresentam redução no custo 
de transporte em comparação com o atual custo de frete da companhia. Além disso, com os resultados gerados foi observada uma mudança no perfil dos veículos que realizam a operação, incluindo também veículos T1, que apesar de menores, são capazes de atender a demanda do período estudado a um custo menor.

Em relação ao número de veículos, a frota da empresa está superdimensionada para o atendimento da demanda das lojas analisadas e existe a possibilidade de redução de custos com a redução do número de veículos.

Respondendo a terceira pergunta de pesquisa proposta neste trabalho, a roteirização que minimiza os custos de frete da empresa é a apresentada no quarto cenário analisado, que propõe que os horários para o atendimento das lojas sejam redefinidos e o tempo médio de descarga seja de $10 \mathrm{~min} / \mathrm{m}^{3}$, podendo gerar assim um ganho financeiro de aproximadamente $32 \%$. Esse resultado é obtido através da utilização de seis veículos divididos entre T1, T2 e T3 para o atendimento das 24 lojas.

Assim, em resumo, além dos ganhos financeiros, a utilização de uma ferramenta de roteirização pode gerar ganhos operacionais, através da redução do número de veículos que precisam ser carregados para atendimento das lojas e consequentemente de mão de obra necessária para carregamento, podendo ser utilizada como uma ferramenta de ajuda na tomada de decisões.

Contudo, esse estudo analisa apenas um conjunto de lojas da companhia localizadas na cidade do Rio de Janeiro, assim a seção seguinte apresenta as propostas de estudos que podem ser desdobradas a partir deste trabalho.

\section{2}

\section{Proposta de Estudos Futuros}

Como proposta para estudos futuros, sugere-se que o modelo utilizado neste trabalho seja aplicado a todas as lojas atendidas pelo centro de distribuição do Rio de Janeiro, que possuem demandas maiores que as lojas analisadas neste estudo, permitindo assim ganhos ainda mais significativos e um dimensionamento mais assertivo da frota necessária. 
As estratégias de abastecimento analisadas neste trabalho também podem ser incluídas no processo de planejamento e geração de rotas para atendimento das lojas da companhia, principalmente para o atendimento de lojas distantes, onde a consolidação de carga pode gerar ganhos mais significativos.

Pode-se também aplicar o estudo aos outros centros de distribuição da companhia, que possuem um perfil diferente de veículos, em função do tamanho e localização das lojas que abastecem.

Ademais, o estudo também pode ser feito para a simulação de novas rotas, considerando-se as lojas que a empresa pretende abrir, assim como a abertura de novos CDs, de forma que uma loja possa ser atendida por mais de um centro de distribuição, além da alteração dos horários de recebimento das lojas, que podem proporcionar rotas mais otimizadas para a operação da companhia e a utilização de hubs como pontos de transbordo de carga, permitindo o transporte de mercadorias em escala e a redução dos custos de frete. 


\section{6 \\ Referências Bibliográficas}

Akyol, D.E., Koster, DE e R.B.M. Non-dominated time-window policies in city distribution. Production and Operations Management. Vol. 22, 3, pp. 739-751, 2013.

Akyol, Derya Eren e Koster, René B. M. De. Determining time windows in urban freight transport: A city cooperative approach. Transportation Research Part E: Logistics and Transportation Review. Vol. 118, pp. 34-50, 2018.

Ala-Risku, T., Karkkainen, M. e Holmstrom, J. Evaluating the applicability of merge-in-transit. The International Journal of Logistics Management. Vol. 14, pp. 67-82, 2003.

Ballou, Ronald H. Gerenciamento da Cadeia de Suprimentos/Logística Empresarial. 5a. s.1. : Bookman, p. 596, 2006.

Barceló, Jaime, Grzybowska, Hanna e Pardo, Sara. Vehicle Routing And Scheduling Models, Simulation And City Logistics. Dynamic Fleet Management. Operations Research/Computer Science Interfaces Series. Vol. 38, pp. 163-195, 2007.

Boloori, A. R. Arabanj, Fatemi, S.M.T. Ghomi e Zandieh, M. Meta-heuristics implemetation for scheduling of trucks in a cross-docking system with temporary sotrage. Expert Systems with Applications. Vol. 38, pp. 1964-1979, 2011.

Bowersox, Donald J.; Closs, David J.; Cooper, M. Bixby; Bowersox, Jonh C. Gestão Logística da Cadeia de Suprimentos. 4ª s.l. : AMGH, 2014.

Bräysy, Olli e Gendreau, Michel. Vehicle Routing Problem with Time Windows, Part I: Route COnstruction and Local Search Algorithms. Transportation Science. pp. 104-118, 2005.

Bretzke, Wolf-Rüdiger. Global urbanization: a major challenge for logistics. Logistics Research. Vol. 6, pp. 57-62, 2013.

Buller, Luz Selene. Logística Empresarial. [ed.] IESDE. p. 126, 2012.

Cachon, Gerard. Managing a Retailer's Shelf Space, Inventory, and Transportation. Manufacturing \& Service Operations Management. pp. 211-229, 2001.

Campbell, J. F. Continuous and discrete demand hub location problems. Transportation Research Part B: Methodological. pp. 473-482, 1993.

Cauchick, Miguel Paulo Augusto. Metodologia de Pesquisa em Engenharia de Produção e Gestão de Operações. s.l. : Elsevier Editora Ltda, pp. 131-148, 2012. 
Chen, J. F.A note on solution of the capacitated single allocation hub location problem. International Journal of Applied Management Science, Vol. 1, pp. 198216, 2008.

Chen, Shyi-Ming e Chien, Chih-Yao. Solving the traveling salesman problem based on the genetic simulated annealing ant colony system with particle swarm optimization techniques. Expert Systems with Applications, Vol. 38, pp. 1443914450, 2011.

Cherrett, Tom \& Allen, Julian \& Mcleod, Fraser \& Maynard, Sarah \& Hickford, Adrian \& Browne, Mike. Understanding urban freight activity - key issues for freight planning. Group of Transport Geography, pp. 22-32, Setembro de 2012.

Choy, K.L. \& Chow, H.K.H. \& Poon, T.C. \& Ho, G.T.s. Cross-dock job assignment problem in space-constrained industrial logistics distribution hubs with a single docking zone. International Journal of Production Research, Vol. 50, pp. 24392450, 2012.

Clarke, G. e Wright, J.W. Scheduling of vehicles from a central depot to a number of delivery points. Operations Research, pp. 568-581, 1964.

Cleophas, Catherine \& Cottrill, Caitlin \& Ehmke, Jan \& Tierney, Kevin. Collaborative urban transportation: Recent advances in theory and practice. European Journal of Operational Research. Vol. 273, pp. 801-816, 2019.

Crainic, Teodor Gabriel, Ricciardi, Nicoletta e Storchi, Giovanni. Models for Evaluating and Planning City Logistics Systems. Transportation Science. Vol. 43, pp. 432-454, Novembro de 2009.

Dablanc, Laetitia. Goods transport in large European cities: Difficult to organize, difficult to modernize. Transportation Research Part A: Policy and Practice, pp. 280-285, 2007.

Danielis, R, Rotaris, L e Marcucci, E. 2010. Urban freight policies and distribution channels. European Transport, pp. 114-146, 2010.

Dantzig, G. B. e Ramsey, J. H. The Truck Dispatching Problem. Management Science. Vol. 6, pp. 80-91, 1959.

Dias, Cleidson Nogueira e Leite, Eduardo Dias. Gerenciamento da Logística no Varejo. Revista Negócios em Projeção. Vol. 2, pp. 53-70, 2011.

Enomoto, Leandro Minoru e Lima, Renato da Silva. Análise da Distribuição Física e Roterização em um Atacadista. Produção. Vol. 17, pp. 94-108, 2007.

Erdoğan, Güneş. An open source Spreadsheet Solver for Vehicle Routing Problems. Computer \& Operations Research. Vol. 84, pp. 62-72, 2017.

Erdoğan, Güneş. User's Manual for VRP Spreadsheet Solver. 2015.

Essafi, Imen, Mati, Yazid e Dauzère-Pérès, Stéphane. A genetic local search algorithm for minimizing total weighted tardiness in the job-shop scheduling problem. Computers \& Operations Research. Vol. 35, pp. 2599-2616, 2008. 
Hesse, Markus e Rodrigue, Jean-Paul. The transport geography of logistics and freight distribution. Journal of Transport Geography. Vol. 12, pp. 171-184, 2004.

Ilos. Armazenagem Estratégica: Analisando Novos Conceitos. 10 de Março de 2000.

Juvella, S. e Vanalle, R. Merge in transit - Uma nova ferramenta logística. XXII Encontro Nacional de Engenharia de Produção, 2018.

Karkkainen, M., Ala-Risku, T. e Holmstrom, J. Increasing customer value and decreasing distribution costs with merge-in-transit. International Journal of Physical Distribution \& Logistics Management. Vol. 33, pp. 132-148, 2003.

Kumar, Suresh Nanda e Panneerselvam, Ramasamy. A Time-Dependent Vehicle Routing Problem with Time Windows for E-Commerce Supplier Site Pickups Using Genetic Algorithm. Intelligent Information Management. Vol. 7, 2015.

Laporte, Gilber. Fifty Years of Vehicle Routing. Trabsportation Science. Vol. 43, pp. 408-416, 2009.

Laporte, Gilbert. The Vehicle Routing Problem: An overview of exact and approximate algorithms. European Journal of Operational Research. Vol. 59, pp. 345-358, 1992.

Laporte, Gilbert. Classical and modern heuristics for the vehicle routing problem. International Transactions in Operational Research. pp. 285-300, 2000.

Leardi, R. Comprehensive Chemometrics. s.l. : Elsevier, 2009.

Leonard-Barton, Dorothy. A Dual Methodology for Case Studies: Synergistic Use of a Longitudinal Single Site with Replicated Multiple Sites. Organization Science. Vol. 1, pp. 248-266, 1990.

Lumsden, K., Dallari, F. e Ruggeri, R. Improving the efficiency of the hub and spoke system for the SKF European distribution network. International Journal of Physical Distribution \& Logistics Management. Vol. 29, pp. 50-66, 1999.

Muñuzuri, Jesús; Larrañeta, Juan; Onieva, Luis; Cortés, Plabo. Solutions applicable by local administrations for urban logistics improvement. The International Journal of Urban Policy and Planning. Vol. 22, pp. 15-28, 2005.

News, Redação Food Service. Lojas de Conveniência. Foodservice News, 2007. [Acessado em: 02 de Junho de 2019.] http://www.foodservicenews.com.br/lojasde-conveniencia/.

Ortigoza, Silvia Aparecida Guarnieri. Paisagens do consumo: São Paulo, Lisboa, Dubai e Seul. s.l. : Editora UNESP, 2010.

Pecin, Diego; Pessoa, Arthur; Poggi, Marcus; Uchoa, Eduardo. Improved branchcut-and-price for capacitated vehicle routing. Mathematical Programming Computation.Vol. 9, pp. 61-100, 2017.

Pisinger, D. e Ropke, S. A General Heuristic for Vehicle Routing Problems. Computers \& Operations Research. pp. 2043-2435, 2007. 
Plural. 29 de Março de 2018. [Acessado em: 02 de Agosto de 2019.] https://somosplural.com.br/biblioteca/conveniencia-no-brasil-do-bola-pesada-asoportunidades-futuras/.

Quak, H. J. e de Koster, M. B. M. Delivering Goods in Urban Areas: How to Deal with Urban Policy Restrictions and the Environment. Transportation Science. Vol. 43, pp. 211-227, 2009.

Raff, Samuel. Routing and scheduling of vehicles and crews: The state of the art. Computers \& Operations Research. Vol. 10, pp. 63-67, 69-115, 117-147, 149-193, 195-211, 1983.

Razmi, J. e Rahmanniya, F. Design of distribution network using hub location model with regard to capacity constraint and service level. International Journal of Logistics Systems and Management (IJLSM). Vol. 16, 2013.

Rodrigue, Jean-Paul e Slack, Brian. Logistics and National Security . Science, Technology, and National Security. Pensylvania Academy of Science Press, Pittsburgh. pp. 214-225, 2002.

Rodriguez, V., Alvarez, M. J. e Barcos, L. Hub location under capacity constraints. Transportation Research Part E: Logistics and Transportation Review. Vol. 43, pp. 495-505, 2007.

Ross, A. e Jayaraman, V. An evaluation of new heuristics for the location of crossdocks distribution centers in supply chain network design. Computers \& Industrial Engineering. Vol. 55, pp. 64-79, 2008.

Serna, M.D.A., Uran, C.A.S. e Uribe, K.C.A. Collaborative autonomous systems in models of urban logistics. pp. 171-179, 2012.

Silva, Edna Lúcia da e Menezes, Estera Muszkat. Metodologia da Pesquisa e Elaboração de Dissertação. $3^{a}$. Florianópolis : Laboratório de Ensino a Distância UFSC, 2001.

Silva, M. R. e Cunha, C. B. Configuração de redes do tipo hub-and-spoke para o transporte rodoviário de carga parcelada no Brasil utilizando algoritmos genéticos. Revista Transportes. Vol. XII, pp. 23-31, 2004.

Sindicom. Combustíveis, Lubrificantes e Lojas de Conveniência, 2017. [Acessado em: 21 de Maio de 2019.] https://somosplural.com.br/wpcontent/uploads/2018/03/anuario_sindicom_2017.pdf.

Subramanian, A., Drummond, L. M. A., Bentes, C., Ochi, L.S., Farias, R. A parallel heuristic for the vehicle routing problem with simultaneous pickup and delivery. Computers \& Operations Research.Vol 37, pp. 1899-1911, 2010.

Subramanian, Anand, Uchoa, Eduardo e Ochi, Luiz Satoru. A hybrid algorithm for a class of vehicle routing problems. Computers \& Operations Research. Vol. 40, pp. 2519-2531, 2013. 
Talon, Juliana Abreu, Nascimento, Daniel e Thomé, Antônio Márcio. Estratégias de Abastecimento em Lojas de Conveniência Localizadas em Centros Urbanos. SIMPEP. 2018.

Taniguchi, Eiichi e Thompson, Russell G. Modeling City Logistics. Transportation Research Record. Vol. 1790, pp. 45-51, 2002.

Vidal, T., et al. A unified solution framework for multi-attribute vehicle routing problems. European Journal of Operational Research. pp. 658-673, 2014.

Wisner, Joel D. e Tan, Keah Choon. Supply Chain Management and Its Impact on Purchasing. Journal of Supply Chain Management, pp. 33-42, 2000.

Yin, Robert K. Case Study Research Design and Methods. 4. s.1. : Sage, Vol. 5, 2009.

Zapfel, G. e Bogl, M. An adaptive structure of a hub-and-spoke system with direct and depot shipments in the case of volatile demand over time. Journal of Business Economics. Vol. 86, pp. 697-721, 2016. 